\title{
COASEAN APPROACHES TO ENDING OVERFISHING: BIGEYE TUNA CONSERVATION IN THE WESTERN AND CENTRAL PACIFIC OCEAN
}

\author{
Daniel Ovando \\ Gary D. Libecap \\ Katherine D. Millage \\ Lennon Thomas \\ Working Paper 27801 \\ http://www.nber.org/papers/w27801 \\ NATIONAL BUREAU OF ECONOMIC RESEARCH \\ 1050 Massachusetts Avenue \\ Cambridge, MA 02138 \\ September 2020
}

The authors thank Josh Abbott, Lee Alston, Alexandra Benham, Lee Benham, Eric Edwards, Joshua Graff Zivin, Corbett Granger, Ron Johnson, Phil Keefer, Dan Holland, Dean Lueck, Dominic Parker, Mary Shirley, Bob Gillett, Chris Costello, Matt Burgess, Dale Squires, and participants at the University of Canterbury (NZ) Erskine Fellowship Workshop and the NCSU and Duke Triangle Resource and Economics Seminar Series (TREE). The views expressed herein are those of the authors and do not necessarily reflect the views of the National Bureau of Economic Research.

NBER working papers are circulated for discussion and comment purposes. They have not been peer-reviewed or been subject to the review by the NBER Board of Directors that accompanies official NBER publications.

(C) 2020 by Daniel Ovando, Gary D. Libecap, Katherine D. Millage, and Lennon Thomas. All rights reserved. Short sections of text, not to exceed two paragraphs, may be quoted without explicit permission provided that full credit, including $\odot$ notice, is given to the source. 
Coasean Approaches to Ending Overfishing: Bigeye Tuna Conservation in the Western and Central Pacific Ocean

Daniel Ovando, Gary D. Libecap, Katherine D. Millage, and Lennon Thomas

NBER Working Paper No. 27801

September 2020

JEL No. Q22,Q28,Q57,Q58

\section{ABSTRACT}

Bigeye tuna in the Western and Central Pacific Ocean were perceived as overfished for nearly 20 years, in large part due to incidental catch in the much larger skipjack tuna fishery. Efforts to halt the overfishing of bigeye stalled due to disagreements over the distribution of costs and benefits from reform. An alternative Coasean-style approach to setting both harvesting levels and the allocation of costs and benefits might offer a path forward. We calculate the costs and benefits of achieving bigeye conservation goals and describe an exchange through which benefits could be realized via removal of Fish Aggregating Devices (FADs). Through trade, aggregate benefits and costs are more apt to be in balance relative to mandated protection controls. The realities of bargaining costs in a multilateral setting are not underappreciated, but in light of existing stalemates in this and other fisheries, consideration of Coasean-style approaches is warranted.

Daniel Ovando

School of Aquatic and Fishery Sciences

University of Washington

Seattle, Washington

danovan@uw.edu

Gary D. Libecap

Bren School of Environmental Science

and Management and Economics Department

University of California, Santa Barbara

Bren Hall 4412

Santa Barbara, CA 93106-5131

and NBER

glibecap@bren.ucsb.edu
Katherine D. Millage

Bren School of Environmental Science

and Management

Santa Barbara, CA 93106

kmillage@ucsb.edu

Lennon Thomas

Sustainable Fisheries Group

Bren School of Environmental Science

and Management

University of California

Santa Barbara, CA 93106

lennon.rose.thomas@gmail.com 
Title: Coasean Approaches to Address Overfishing: Bigeye Tuna Conservation in the Western and Central Pacific Ocean

Short Title: Coasean Bargaining to Address Overfishing

Key Words: Coasean Bargaining, Bigeye tuna, overfishing, conservation payments

JEL Codes: Q22, Q57

Authors: Daniel Ovando ${ }^{a}$, Gary D. Libecap ${ }^{b, c}$, Katherine D. Millage ${ }^{b}$, Lennon Thomas ${ }^{b}$

Date: August 28, 2020

Abstract: Bigeye tuna in the Western and Central Pacific Ocean were perceived as overfished for nearly 20 years, in large part due to incidental catch in the much larger skipjack tuna fishery. Efforts to halt the overfishing of bigeye stalled due to disagreements over the distribution of costs and benefits from reform. An alternative Coasean-style approach to setting both harvesting levels and the allocation of costs and benefits might offer a path forward. We calculate the costs and benefits of achieving bigeye conservation goals and describe an exchange through which benefits could be realized via removal of Fish Aggregating Devices (FADs). Through trade, aggregate benefits and costs are more apt to be in balance relative to mandated protection controls. The realities of bargaining costs in a 
multilateral setting are not underappreciated, but in light of existing stalemates in this and other fisheries, consideration of Coasean-style approaches is warranted.

Acknowledgements: The authors thank the Editor and two anonymous referees, as well as Lee Alston, Alexandra Benham, Lee Benham, Eric Edwards, Joshua Graff Zivin, Corbett Granger, Ron Johnson, Phil Keefer, Dan Holland, Dean Lueck, Dominic Parker, Mary Shirley, Bob Gillett, Chris Costello, Matt Burgess, Dale Squires, and participants at the University of Canterbury (NZ) Erskine Fellowship Workshop and the NCSU and Duke Triangle Resource and Environmental Economics Seminar Series (TREE).

\section{Affiliations:}

a School of Aquatic and Fishery Sciences, University of Washington, Seattle, Washington ${ }^{\mathrm{b}}$ Bren School of Environmental Science \& Management, University of California, Santa Barbara, California

${ }^{c}$ Department of Economics University of California, Santa Barbara, California

Correspondence: Daniel Ovando, School of Aquatic and Fishery Sciences, University of Washington, 1122 NE Boat St., Box 355020, Seattle, WA 98195 | Email: danovan@uw.edu | Phone: (206) 543-4270

\section{INTRODUCTION}


Best available evidence from 2001 to 2014 indicated that bigeye tuna (Thunnus obesus) in the Western and Central Pacific Ocean (WCPO) were being overfished, largely via incidental catch of juvenile bigeye by purse-seine vessels targeting skipjack tuna (Katsuwonus pelamis, whose population is estimated to be above management targets (Rice et al. 2014)). Juvenile bigeye are caught as they school with skipjack under fish-aggregating devices (FADs) used by the skipjack fleet to raise catch-per-unit-of-effort (CPUE) and to lower search costs (Harley et al. 2014). While the most recent bigeye stock assessment suggests that overfishing is no longer occurring (McKechnie et al. 2017), this change is driven by changes in our understanding of the species' biology, not as a result of management reforms (McKechnie et al. 2017). We seek to understand why perceived overfishing persisted for so long despite regulatory efforts, and to identify what new solutions might be available.

The WCPO hosts the world's largest tuna fisheries, producing $55 \%$ or more of the total tropical tuna catch (FAO 2016). The region hosts a diverse group of fishing fleets, ranging from small artisanal vessels to industrial purse-seine, pole-and-line, and longline fleets from at least 26 nations. The industrial fleets harvest skipjack, yellowfin (Thunnus albacares), bigeye, and albacore (Thunnus alalunga) tunas. The purse-seine skipjack fishery is the most valuable in the region, accounting for over half of total catch value (Williams and Reid 2018). The regulatory body charged with management of the WCPO tuna stocks, the Western and Central Pacific Fisheries Commission (WCPFC), implemented six Conservation and Management Measures (CMMs) between 2005 and 2014 to remedy bigeye overfishing through effort controls, temporal restrictions on FADs, and spatial closures. ${ }^{1}$ These actions,

\footnotetext{
${ }^{1}$ The WCPFC is comprised of 26 member nations, 7 additional participants, and 7 non-member cooperating countries
} 
however, reduce the net value of skipjack harvests, and have been resisted by skipjack fishing interests. More rigorous mitigation efforts have not been adopted due to disagreements among the parties over bigeye stock targets and the distribution of costs and benefits necessary to achieve them (Hanich 2012).

In this paper we explore this stalemate over remedies to perceived overfishing of bigeye tuna. To do this, we estimate the overall benefits and costs of various conservation goals, and provide an alternative Coasean-style bargaining approach to move beyond impasse, potentially delivering additional bigeye protection and better balancing aggregate net gains across fleets. Our bio-economic simulation model provides estimates of the costs of reduced skipjack harvest revenues with FAD reductions necessary to achieve bigeye stock objectives and to gain associated bigeye revenues. Economic objectives are measured in tradeoffs: lost value in skipjack revenues versus gained revenues of bigeye.

Since the WCPFC Scientific Committee's 2001 stock assessment, there have been concerns about bigeye overfishing by the skipjack fleet. Evidence of regulatory effectiveness, bigeye stock conditions, and the need to take further action, however, are mixed. The 2014 stock assessment indicated continued overfishing (Harley et al. 2014), but the most recent assessment no longer estimates excessive harvest (McKechnie et al. 2017). This view appears driven by changes in the biological structure of the model, however, and not by reductions in mortality stemming from management changes. Even with a more optimistic assessment, if the 2013 - 2015 trends in fishing mortality and long-term juvenile recruitment

https://www.wcpfc.int/home. 
continue, bigeye mortality rates could exceed regulatory targets by 2022; the region may still be in need of a solution to bigeye overfishing in the future (WCPFC 2018).

There are 325 active skipjack purse-seine vessels and 2,634 active bigeye longline vessels (Escalle et al. 2018) from different countries (Fig. 1) in the WCPO. Longline fleets from Japan, South Korea, China, Indonesia, Vanuatu, Solomon Islands, and Fiji harvest mature bigeye, while purse-seine fleets from Papua New Guinea, the USA, Spain, Philippines, Kiribati, Marshall Islands, Ecuador, and El Salvador target skipjack (and incidentally, capture juvenile bigeye). Taiwan, Vietnam and the USA have vessels in both fisheries. Skipjack is harvested primarily for canning in Thailand, the world's largest cannedtuna producer. ${ }^{2}$ The direct beneficiaries of improved bigeye stocks are longline fleets that target bigeye and consumers in the Japanese sashimi market (Bailey et al. 2013, 55-56). There also are intrinsic values and ecosystem services provided by bigeye tuna of particular concern to members of conservation NGOs. For example, groups such as The Nature Conservancy already have supported numerous programs focused on reducing bycatch of bigeye tuna at a cost of $\$ 1.5$ million USD (Ginn 2020; O'Connor 2016)

An estimated 38,000-48,200 FADs were used in the WCPO in 2017, more than 100 per purse-seine vessel (Escalle et al. 2018). Skipjack tuna and juvenile bigeye that congregate below FADs are caught by the purse-seine fleet (Hampton and Fournier 2001; Allen et al. 2010; Juan-Jordá et al. 2011). On average, only $\sim 4 \%$ of the total FAD catch in the skipjack-targeting fishery is bigeye, but due to the volume of the skipjack purse-seine fishery, this bycatch accounts for roughly $50 \%$ of bigeye biomass caught each year (Davies et al.

2 Thailand processes over half of the global skipjack harvest (Sibert et al. 2012; Williams and Reid 2018). About $70 \%$ of US canned tuna comes from Thailand (Sun et al. 2015). 
2011). Past seasonal FAD closures have yielded significant reductions in bigeye catches and generated increases in the average size of individual bigeye fish caught during the closure period (Havice 2013). Based on this experience and simulated fish size and stock responses, dramatic or total removal of FADs in the skipjack fishery has been suggested (Bailey et al. 2013). Although doing so would reduce bigeye mortality, it would likely imbalance total gained social benefits and costs and impose disproportionate costs on the skipjack purseseine fleet.

A review of WCPFC documents from 2005-2016 reveals the divisions that occur among members in confronting bigeye overfishing (Hanich 2012). ${ }^{3}$ Differences in the expected benefits and costs of regulation underscore the varying positions of country representatives and explain why more concerted action to protect bigeye was not taken.

\section{REgULATORY SOLUTIONS TO OVERFISHING}

\section{Traditional Pigouvian-style Regulation}

FADs are valuable for the skipjack purse-seine fleet because they lower private fishing costs. Their use, however, inflicts external costs on bigeye longline fishers, Japanese consumers, and those in conservation NGOs, who value bigeye as part of the natural ecosystem. These negative effects are not weighed by skipjack fleet owners in fishing decisions so that the marginal private costs of FAD use are less than marginal social costs. In

\footnotetext{
${ }^{3}$ Such stalemates are found in other settings, such as the overfishing of Pacific Bluefin tuna (Thunnus thynnus) (ISC 2016; Pons et al. 2016) and over-drafting of California groundwater (Ayres et al. 2018).
} 
the absence of property rights - a setting that characterizes most fisheries - the traditional regulatory response to internalize the externality raises private costs to achieve a more optimal level of harvest, in this case to reduce bigeye bycatch. This approach imposes "polluter pays" restrictions and follows from the work of (Pigou 1932, Part II, Chapter IX: 6777)

Pigou argued that if the marginal private net product exceeded the marginal social net product, arising when private costs were below social costs, the former could be raised through government intervention to remove the divergence and be welfare improving. Pigouvian taxes, for example, would be a correction. Sufficiently-calibrated Pigouvian taxes, however, are rarely observed in fisheries or in other natural resource management. Instead, fishery regulation primarily relies upon input and output controls that constrain access, effort, or harvest to levels set by the regulator, often to achieve a yield-based objective, such as maximum sustainable yield (MSY). ${ }^{4}$ Regulatory costs are imposed on harvesters to more completely internalize the externality through defined fishing seasons or fishing days, limits on vessel size and capacity, equipment and gear restrictions, designated restricted areas and limited entry, and/or catch limits and minimum landing sizes.

Efforts to address bigeye overfishing in the WCPO reveal a number of potential problems with a Pigouvian approach. First, there are clear costs from reduced FAD use by

\footnotetext{
${ }^{4}$ These restrictions may or may not coincide with those associated with Pigouvian taxes where marginal private net product $($ MPNP) $=$ marginal social net product (MSNP). See Weitzman (1974) for an analysis of the similarities and tradeoffs in use of prices (taxes) versus quantities (input or output controls) in response to externalities. Weitzman (2002) applies these arguments to fishery management where he models optimal escapement levels via the use of taxes or quotas following experience with Iceland's fisheries where quota policies have dominated. He finds that in the presence of ecological and economic uncertainty Pigouvian taxes always dominate quotas. Tax revenues could then be used to address unfairness in the quota system. Weitzman does not examine regulatory costs nor political/bureaucratic incentives in setting optimal policies or in adjusting them in response to uncertainty. These issues are beyond the scope of his paper, but are relevant for calling for Pigouvian taxes and compensatory payments.
} 
the skipjack fleet, but no commensurate benefits to the skipjack fleet from a bigeye rebound. ${ }^{5}$ In this case, regulatory intervention makes skipjack fleet owners and related consumers worse off (in a general setting, see Sallee 2019). This result generates incentives to resist and delay action against overfishing, as has occurred already within the WCPO tuna fisheries. This motivation raises enforcement costs and undercuts achievement of conservation objectives. Additionally, the absence of property rights in traditional regulation prevents skipjack and bigeye fishers from bargaining privately within or across fleets for marginal adjustments in response to changes in local costs and benefits or to reallocate fishing effort. Under traditional regulation, there is no easy mechanism for such internal tradebased adjustments to take place. ${ }^{6}$ The parties must go through the regulatory process, and if it is complex and costly, valuable responses could be delayed or blocked. ${ }^{7}$

Finally, standard regulation to internalize the externality motivated, for example, by yield-maximizing objectives, does not inherently match total social costs and benefits.

\footnotetext{
${ }^{5}$ Bailey et al. $(2013,56-60)$ call for a cooperative approach to overcome disparities in the distribution of benefits and costs in WCPO tuna regulation, but a Pigouvian approach for example, that requires reductions in valuable FAD use by skipjack fleets as "polluter pays" provides no obvious mechanism for cooperation or lump-sum transfers as mitigation. As we point out, such fully-compensating monetary transfers are rare in fisheries as in other resources, explaining in part, why intervention often is so controversial.

${ }^{6}$ Lump-sum payments to offset opposition are rare to find in fisheries or other natural resource settings. The 2007 purchase by The Nature Conservancy (TNC) of 7 federal trawling permits for commercial groundfish and 4 vessels from fishers on the Central California Coast. Permits and vessels were then leased back to fishers who complied with fishing restrictions. TNC bought them to conserve depleted seafloor species (Deacon and Parker 2009; Gleason et al., 2013). Because the acquisition was self-financed by TNC for $\$ 3.8$ million (Deacon and Parker 2009) and the leases were bought by fishers, the exchange better reflected a balancing of benefits and costs than would mandated conservation controls. Vessel buybacks and other forms of direct compensation to fishers also pay for losses in setting conservation goals, lower the costs of achieving those goals, and require balancing of tradeoffs (Holland et al. 1999, 100; 2017; Squires 2010). The benefits of buyback, however, unravel if reentry is not deterred.

${ }^{7}$ As an indication of the complexities of the regulatory process in securing or changing payments as more information is revealed, consider on-going controversies compensation provided to fishing interests in expansion of the Great Barrier Reef Marine Park (W. J. Fletcher et al. 2016; Warrick Jeffrey Fletcher et al. 2014; Gunn, Fraser, and Kimball 2010; Hughes et al. 2016; McCook et al. 2010).
} 
Property rights in the fishery are not assigned that otherwise would lead parties to weigh tradeoffs more completely. There could be too much or too little intervention from a social netgains point of view. As our calculations reveal, the total value of lost skipjack harvests to achieve standard MSY objectives for bigeye $\left(S S B / S S B_{M S Y}=1, S S B\right.$ stands for spawning stock biomass), far exceeds any expected fishery benefit from larger bigeye stocks. In accomplishing the objective, society would be made worse off in terms of fishery benefits while the narrower bigeye constituency would see improvement. Within the WCPFC, skipjack interests have opposed more concerted efforts to reduce overfishing. Our estimates identify which conservation goals could be welfare-improving, and we then suggest how those objectives might be achieved. ${ }^{8}$

\section{A Coasean-Style Alternative}

Coase (1960) offered an alternative to traditional Pigouvian-style regulation that we adopt in the case of WCPO skipjack and bigeye tuna fisheries. The assignment of tradable property rights would allow bargaining within and across the fisheries to set both bigeye

\footnotetext{
${ }^{8}$ More broadly, in other fishery settings, constraints can be imposed by the regulator at the behest of organized constituents who do not bear the full social costs of achieving their objectives. Costello and Grainger (2018) are unusual in modeling regulatory responses to lobbying and then test the implications of their model using a global fishery dataset. They acknowledge that the regulator may not impose policies that are in society's general interest. The lobbyists in their framework are fishers with different property rights security. They find that those with more secure rights seek more conservative management by the regulator in setting TACs. They also suggest that if fishery lobbyists have weaker claims over future policies, the regulator would more likely act to maximize the resource's value to society. Johnson and Libecap (2001) describe the importance of competitive lobby groups. Volden and Wiseman (2007) examine the incentives of legislatures to respond to particularistic constituent demands as compared to providing general social benefits.
} 
conservation targets and the distribution of costs and benefits of achieving them. ${ }^{9}$ With rights granted to skipjack vessel owners, for example, those seeking greater conservation of bigeye would pay to reduce harvest through FAD reductions, internalizing more regulatory costs. Alternatively, if rights were granted to bigeye fishers, purse-seine vessel owners would pay for additional harvests, internalizing more exploitation costs. In either case, the parties that valued additional cutbacks or harvests would buy rights to achieve them. A voluntary, incremental exchange that balanced willingness-to-pay with willingness-to-accept would be Pareto improving. Moreover, within the two fleets, property rights could be exchanged in response to differential values and costs of harvest and of complying with FAD reductions.

Cross-fishery trade continues so long as one party values conservation or harvest

more than the other and ceases when relative values are balanced. Because trade could take place whenever each party's costs or benefits from conservation or harvest change, the extent of total skipjack/bigeye harvest control is flexible. Through trade, bigeye harvests would gravitate to the parties that valued exploitation or protection the most. Because traders hold property rights in this Coasean scenario, they internalize more of the private and social costs associated with different levels of fishing or conservation.

\footnotetext{
${ }^{9} \mathrm{~A}$ common concern with the use of Coasean-style approaches is the transaction cost of assigning and trading property rights. These costs could be large, but a comparative institutional analysis is critical. There are wellknown costs in assigning property rights to support trade, as recognized by Coase (1960, 15-19), Libecap (2007), and Grainger and Parker (2013). There are, however, additional regulatory costs that neither Coase nor many of his critics examine (Medema 2014). Both the assignment of property rights and subsequent trade as well as regulation use real resources and hence, are relevant in assessing institutional alternatives. For traditional fishery regulation, there are the agency costs of securing and analyzing reliable information about harvests and stock conditions; there are lobby costs as interest groups that advocate either extended harvests or conservation, seek to influence the agency or its political sponsors; there are the costs of setting, monitoring, and enforcing harvest restrictions that are not independent of the regulations adopted; and there are the costs of modifying regulation if costs and benefits importantly change. A case-by-case analysis is required to determine which approach is less socially costly.
} 
The property rights vehicle for exchange are FADs. Because skipjack fleets have historical use in FAD fishing, we assume they have grandfathered property rights such that bigeye interests would compensate them for lost production as "beneficiary pays." 10 We have information on the latitude, longitude, month, FAD type, and vessel in our bio-economic model to estimate reduction in bigeye incidental harvest (bigeye revenue saved) and skipjack-targeted harvest (skipjack revenue lost) for each FAD that is removed. We rank FADs in descending order, according to the ratio of bigeye revenue saved relative to skipjack revenue lost as FADS are sequentially eliminated to achieve a particular conservation target. While FAD reduction could lead to greater value in the bigeye fishery, it imposes costs of reduced skipjack harvest, and these losses grow as more FADs are jettisoned.

Economic tradeoffs are valued as the present value of lost skipjack revenue from various FAD reductions versus the gained present value of bigeye revenue. Conservation objectives are measured as the resulting spawning biomass of bigeye tuna stocks relative to the spawning stock biomass estimated to produce MSY $\left(S S B / S S B_{M S Y}=1\right)$. The values are outlined in Table 1. Overall bigeye conservation benefits include both market and non-market ecological values. The cost of lost skipjack harvest values suggest what total market and non-market bigeye benefits would have to be in order for the outcome to be welfare enhancing, whereby total benefits/total costs $=1) .{ }^{11}$

There are two valuable attributes to this approach. One is that in the case at hand, assignment of property rights and payments via exchange can reduce opposition from

\footnotetext{
${ }^{10}$ Alternatively, if bigeye interests held the property rights, then skipjack producers would pay for the right to use FADs as "polluter pays."

${ }^{11}$ Kotchen and Burger (2007) outline a similar approach in ANWR oil production controls when environmental benefits are difficult to measure.
} 
skipjack vessel owners against FAD reductions needed to lower bigeye overfishing. The stalemate can be broken and conservation efforts within the WCPFC potentially can proceed. Second, exchange forces both parties to weigh tradeoffs more completely in setting or opposing conservation goals. Skipjack vessel owners would face opportunity costs in considering offers from bigeye conservation advocates to reduce FAD use. Similarly, bigeye conservation advocates would face opportunity costs in considering how much is gained in bigeye protection relative to the costs of FAD reduction.

Payments for FAD reductions occur through transferable Vessel Day Scheme (VDS) licenses. The VDS system provides access to the waters of Parties to the Nauru Agreement countries (PNA). The VDS was implemented in December 2007 as an amendment to the Nauru agreement by the PNA countries, whose EEZs together are responsible for more than $60 \%$ of the total volume of tuna caught in the WCPO (Havice 2013) and 50\% of skipjack tuna harvested globally (Bernadett 2014). ${ }^{12}$ VDS licenses represent fishing days that are set by PNA members annually as Total Allowable Effort (TAE) ${ }^{13}$ PNA countries allocate the TAE among themselves based on relative productivities and histories of fishing effort in their EEZs. Each country's allocated fishing days are sold directly to purse-seine vessel owners. A fishing day purchased gives the corresponding vessel owner the right to fish during a 24-hour

\footnotetext{
12 The 8 PNA countries responsible for implementing the VDS were the Federated States of Micronesia, Kiribati, the Marshall Islands, Nauru, Palau, Papua New Guinea, the Solomon Islands, and Tuvalu. Tokelau joined the VDS in 2012, though it is not a Party to the Nauru Agreement. https://www.ffa.int/nauru agreement; https://www.ffa.int/wcpfc. The governments of the PNA countries receive up to $98 \%$ of their revenues from the sale of tradable VDS fishing days (University of New South Wales 2019).

${ }^{13}$ In 2018 TAE was 44,033 days. A small portion of the TAE is allocated directly to vessels licensed under two treaties (the FSM Arrangement and the US Treaty), both of which allow for greater flexibility regarding where licensed vessels are able to use their vessel days in exchange for other economic activities in the region.
} 
period in the EEZ of the PNA country from which it was purchased. ${ }^{14}$ VDS licenses are transferable across vessels, and purchasers are bound by the total fishing days authorized by the VDS licenses held in a particular year (Bernadett 2014). ${ }^{15}$

This Coasean-style approach lowers transaction costs by both leveraging existing VDS fishing days as well as by targeting payments to the relatively small and concentrated skipjack purse-seine fleet. Enforcement is feasible because the purse-seine fleet has $100 \%$ observer coverage, and data that include the position and species composition of catch from each net set are submitted electronically.

The value of a VDS license is a function of expected harvest net revenues that in turn are affected by the ability to use FADs. If FADs are restricted in a particular area, the direct value of VDS licenses to purse-seine vessel owners falls. To prevent this and to avoid losses to PNA countries, bigeye conservation interests would compensate vessel owners who own VDS licenses for the difference in license value with FAD fishing and FAD-free (termed freeschool) fishing. They would pay to have FADs removed until the expected benefits of additional FAD reduction were less than the expected costs of achieving it. Overall demand for VDS licenses would not change and revenues to PNA countries would not be affected. The resulting number of FAD days removed would then be a function of the expected benefit of FAD removal to the bigeye interests (the willingness-to-pay) and the expected costs of switching to FAD-free fishing by the purse-seine vessels (willingness-to-accept). The parties would negotiate, comparing bid and ask prices, until an equilibrium value is reached that

\footnotetext{
${ }^{14}$ PNA countries are also allowed to buy and sell fishing days from their own allocations among one another to satisfy demand for fishing in waters beyond those allocated.

${ }^{15}$ Monitoring of location, speed, course, and harvest is requited for VDS traders (Bernadett 2014, 113).
} 
determined the feasible conservation goal. If a more aggressive conservation objective were desired, outside support as conservation payments would be required. These payments could come, for example, from NGOs whose membership valued the ecological benefits of greater bigeye stocks. We outline options below.

\section{METHODS}

All data on bigeye and skipjack catches and effort by space, time and gear, were obtained from the WCPFC online portal, accessed on July 17, 2017. The methods used to estimate the effects of FAD removal on catches of bigeye and skipjack are illustrated in Fig. 2.

The core of our estimation method is a monthly age-structured, multi-fleet (longline, FAD-associated purse seine, and free-school purse seine) population model for the bigeye population. The model was tuned to reflect the dynamics of the last stock assessment for bigeye tuna in which overfishing was estimated to be occurring (Harley et al. 2014, Fig. 2.1). We estimated the effect of moving from FAD fishing to free-school fishing on catch rates of skipjack and bigeye by purse seiners in the WCPO ('FAD effects') using a random forest model (Breiman 2001), implemented through the ranger package in the $R$ language ( $R$ Core Team 2019; Wright and Ziegler 2017). The model is of the form:

cpue $_{s, i}=f\left(\right.$ fad $_{i}$, lat $_{i}$, lon $_{i}$, sst $_{i}$, year $_{i}$, month $\left._{i}\right)$ 
where $s$ denotes species (bigeye or skipjack), $i$ is observation, lat is latitude, lon is longitude, sst is sea-surface temperature, year is the year, month is the month, and fad is the type of FAD used (Fig. 2.2 - Fig. 2.3). See online-only appendix for model validation steps.

Using our random forest model, we calculate a FAD-removal effect for each FADassociated set in the database by predicting the CPUE that would have occurred for a given set without a FAD and comparing that CPUE to the observed with-FAD CPUE. This process provides an estimate of the change in expected CPUE and subsequent catch that would result if we were to switch a given instance of FAD-associated fishing to free-school fishing. Each instance of FAD-associated fishing is then ranked in descending order, such that the first FAD removed provides the most reduction of bigeye and the least reduction of skipjack, and so on. The total amount of bigeye saved/skipjack lost from removal of N FAD days is the sum of the FAD-associated fishing instances switched to free-school fishing. We use the Baranov equation (Baranov 1918) to convert the new catch for the Nth scenario into a fishing mortality rate (Fig. $2.4-2.5)$.

For a given number of FAD-associated fishing instances removed, we used our population model to project the effects of eliminating N FAD days from the WCPO forward in time (starting from our approximation of the most recent bigeye stock reported in Harley et al. (2014)). When $N=0$, this projects a scenario in which fishing mortality rates are held constant at the most recently observed values. For each $N>0$, we estimate a future state of the fishery, holding FAD-removal reduced fishing mortality rates constant. Given these future trajectories, we compare skipjack and bigeye fishing revenues with FAD removals to those under 'Business As Usual' (BAU), providing an estimate of the gains and losses to each fishery from moving to free-school fishing (Fig. 2.6 - 2.7) 


\section{RESULTS}

We restrict our analysis to FAD days reported inside EEZs covered by the VDS. Examining first the raw reported FAD-associated CPUE data, areas in the northeastern and central regions of the WCPO have higher median catch rates of bigeye to skipjack, while areas to the northwest and south have lower median catch rates (Fig. 3), which is a similar finding to Kawamoto and Nakamae (2017). The median catch rate of bigeye to skipjack is highest in the Northern Hemisphere summer months and lowest in the winter.

Using our model, we can convert these raw CPUE values into ratios of expected bigeye "saved" to skipjack "lost" as a result of moving from FAD-associated to free-school fishing. ${ }^{16}$ In nearly all regions and months, the expected reduction in CPUE of bigeye is far less than the expected reduction in skipjack CPUE resulting from FAD removal. The northeastern portions of the WCPO, along with the months of August and September, appear to provide the most favorable FAD effects in terms of cost-effective bigeye conservation (Fig. $4)$.

We find that in most circumstances removing FADs produces greater reductions in volume of skipjack catches than it does in bigeye catches. The immediate direct fishery benefit/cost ratios are less than 1, Fig. 4. All else equal, however, bigeye are more valuable if allowed to escape the FAD fishery. Recent prices paid for fresh or frozen mature bigeye in the Japanese market $(\$ 9,370 / \mathrm{MT})$ are approximately five times greater than the price paid

\footnotetext{
${ }^{16}$ The model sorts the results by differences, not ratios, but the results are qualitatively the same and the ratios are clearer to visualize.
} 
$(\$ 1,782 / \mathrm{MT})$ for juveniles caught by the skipjack purse-seine fleet and combined with skipjack for canning in Thailand (Sibert et al. 2012; Williams and Reid, 2018).

The 2014 bigeye stock assessment indicated that fishing mortality rates were near 1.5 times the target level. Under the model assumptions, over time the bigeye population will be driven down to overfished levels, meaning that reducing bigeye catches today could produce an increased population and value of catches of bigeye in the future, relative to the eventually overfished counterfactual. This suggests that even if the bigeye-to-skipjack ratio of removing a FAD is less than one today, removing that FAD may provide a greater net benefit relative to BAU over the long-term, once price and population effects are considered.

\section{ThE TRADEOFFs OF CoAseAN-Style EXCHANGE}

This case study of bigeye tuna in the WCPO demonstrates how Coasean-style approaches might be used to resolve impasses in fisheries and to achieve broader welfareenhancing outcomes. For nearly two decades there was general consensus among stakeholders that the bigeye tuna population was being overfished. Despite this understanding, the WCPFC was unable to reduce harvest of bigeye to recommended levels through standard "polluter-pays" regulatory measures.

We use our bio-economic model to simulate the economic and ecological costs and benefits of increasing levels of FAD removal from the waters covered by the VDS to better understand the sources of dispute. Conservation outcomes are measured by SSB relative to that which would produce MSY at equilibrium $\left(\mathrm{SSB}_{M S Y}\right)$, or $\mathrm{SSB} / \mathrm{SSB}_{M S Y}$ values near 1.

From a purely direct fishery revenue perspective, we estimate that the economic costs of large-scale reductions in FAD use far outweigh the benefits. Non-monetary ecological 
benefits would have to be substantial to support widespread elimination of FADs. By explicitly linking economic costs and benefits to conservation goals, we provide estimates of the net deficit in value that must be overcome in order to gain support for overfishing reduction from fishery interests. The most feasible option is a subsidy of FAD-free fishing of the skipjack fleet, funded by direct contributions from conservation NGOs, price increases on long-line caught bigeye by Japanese consumers, price premiums on certified FAD-free canned skipjack tuna, or a combination of the three. We examine these options below (Fig. 5). Our proposed Coasean-bargaining solution outlines how the voluntary exchange would take place. Bigeye conservation interests would start with the purse-seine fleet operating in the northeast WCPO area under the VDS. This is the region of greatest bigeye mortality/FAD (Fig. 3). They would continue to bankroll the difference between the VDS license price and its loss in value due to diminished CPUE from FAD reduction faced by participating purse-seine vessel owners until the conservation objective at the time was met. Other purse-seine vessels would be free to use FADs with unsubsidized licenses under the VDS.

This negotiated process better aligns costs and benefits and makes Pareto-improving change in the fishery possible. As part of the exchange both parties more completely weigh tradeoffs in selecting FAD reductions and corresponding bigeye conservation goals. Coasean-style exchange is open to new entrants. For example, if other conservation interests believed or new information suggested that greater reductions in FAD use were required, they could subsidize additional VDS licenses with lower or no FADs (Bell, Peacey, and Stokes 2015). Moreover, across the WCPO other purse-seine vessel owners could apply for license subsidies and reduce FAD use. The attractiveness of participation would depend on the impact of a given FAD instance on bigeye mortality and subsequent willingness to pay by 
conservation interests, available funding, as well as the match between the payment conservation groups would be willing to make and reduced CPUE expected by the skipjack fleet. Throughout this process, revenues to VDS participating countries and political units would not change.

We estimate that a mandatory Pigouvian-style restriction aimed at achieving MSY for bigeye through FAD removal alone would require roughly $67 \%$ of the FADs covered by VDS licenses to be removed, resulting in a net loss in skipjack revenues of NPV $\$ 3.3$ billion (Table 1; Fig. 5A) and imposing potential costs on VDS member countries through reduction in demand for licenses if demand were not sponsored by conservation interests seeking bigeye protection. The skipjack revenue loss is roughly 1.75 times the added bigeye revenues of NPV \$1.9 billion, producing a net deficit in direct fishery value.

The skipjack losses would primarily affect major FAD-associated skipjack fishing countries in the WCPO, such as Papua New Guinea, the Philippines, and the USA (as well as countries that depend on the skipjack industry for revenues), and the bigeye benefits would flow to Japanese consumers of longline-caught bigeye and to countries with longline fleets such as China, South Korea, and Indonesia (Fig. 1). These estimates reveal why controls to bring bigeye stocks to MSY levels have been so contentious among the various parties of the fishery.

Non-fishery values would have to be very high to overcome the direct fishery costs of substantial FAD removal. Approximating non-fishery value as the value of net fishery losses, we estimate that complete removal of VDS associated FAD days would require that the indirect value in the fishery have an NPV of approximately $\$ 3$ billion, corresponding to annuity payments of $\$ 15,000$ per year per FAD-day (Line 7, Table 1; Fig. 5D). To place this in 
context, VDS licenses have been selling between $\$ 9,000$ and $\$ 13,000$ (FFA 2017). Achieving a more moderate target of $\mathrm{SSB} / \mathrm{SSB}_{M S Y}=1$ by bigeye fishing and conservation contributions alone would require annuity payments of $\$ 10,000$ per FAD-day per year (Line 5, Table 1; Fig. 4D).

Only limited FAD removals within the VDS system produce fishery benefits greater than or equal to fishery costs (Fig. 5A). A $15 \%$ reduction of FADs leads to a projected bigeye $\mathrm{SSB} / \mathrm{SSB}_{M S Y}$ of between 0.6 and 0.7 , with bigeye benefits of NPV $\$ 0.21$ billion at a cost to skipjack fleets of NPV $\$ 0.17$ billion (Table 1; Fig. 5A). Under the generous assumptions of this model, there is some potential direct fishery surplus that could be used to produce Pareto-improving reduction in FAD use with payments from bigeye fishing interests to skipjack vessel owners via the VDS subsidy.

The viability of these options would depend on the value placed on bigeye conservation by purse-seine vessel owners (potentially to avoid more stringent controls), consumers, and the conservation community. While it is unclear what amount could be raised from conservation interests that have a demonstrated track record of funding efforts to improve the bigeye stock, our analysis demonstrates the magnitude of the values required to achieve substantial gains in the future bigeye stock through a Coasean-style exchange.

How might additional payments be obtained to achieve more substantial conservation improvements in a Pareto-improving manner? One source is a tax levied on consumption of longline-captured bigeye (the beneficiaries of FAD removal) primarily in Japan, with the proceeds funding the removal of FADs. With a direct tax on longline-caught bigeye tuna, bigeye consumers in Japan would need to place an extremely high value on longline-caught bigeye to achieve substantial conservation gains, requiring a $60 \%$ tax to achieve an 
$\mathrm{SSB} / \mathrm{SSB}_{M S Y}$ of 1 (Fig. 5B). Another source is direct payment from conservation groups whose members highly value bigeye stock improvements or other FAD-associated factors such as reduced bycatch of sharks and sea turtles and related ecosystem improvements (Dagorn et al. 2013). A third source is a price premium assigned to certified FAD-free canned skipjack tuna, under the assumption that some skipjack consumers receive an intrinsic benefit from bigeye conservation. ${ }^{17}$

Our model estimates that a $4 \%$ price premium on free-school skipjack would be sufficient to fund the complete removal of FAD fishing from the VDS. This value is calculated as the percent increase in canned skipjack price required to offset lost skipjack catches, Fig. 5C. ${ }^{18}$ These estimates would depend on the elasticity of demand and numerous other assumptions, but provide illustrative benchmarks as to where a tax could be focused. A canned tuna tax could most feasibly be implemented in three markets, the US, France, and the UK that are the leading canned skipjack-importing countries. Elasticity of demand estimates for FAD free tuna depend upon the market segment, consumer environmental concerns, and availability of substitutes. Estimates indicate that elasticity is close to 1 , implying that total revenues would not change (Sun et al. 2017; Sun et al. 2015). The three payment options could be combined to assemble the required amounts.

This analysis potentially also applies to other fisheries where imbalances may not be so stark. In those fisheries such a bargain potentially could set management targets that are more socially beneficial, rearrange costs and benefits, and resolve regulatory logjams.

\footnotetext{
${ }^{17}$ This option is less Coasean because it taxes skipjack consumers as "polluter pays."

18 The values in Fig. 5B-C are calculated from the data underlying Fig. 4 by taking the deficit in the cost/benefit ratio and calculating the percentage gain in the price of sashimi bigeye or canned skipjack required to make up the deficit assuming demand is perfectly inelastic, an issue addressed in the text.
} 
Our model is very stylized: We omit complexities related to the spatial-temporal dynamics of tuna populations and fishing fleets. We do not account explicitly for price elasticities for bigeye or skipjack. We also assume that the outcomes of FAD reduction are constant and deterministic, when they are likely to be context-dependent and stochastic. The assumptions can be refined if the concepts discussed here were to be applied in a more tactical manner. The simplifying assumptions are illuminating since they are optimistic, meaning that this analysis provides a likely upper bound on the potential surplus available for a Coasean-style bargain.

Accounting for uncertainty in future benefits and costs of FAD reduction, for example, potentially reduces the willingness-to-pay by bigeye conservation advocates while increasing the payments required to the skipjack industry. Additionally, increases in bigeye prices resulting from reductions in the bigeye stock under current practices could narrow the gap between the two parties, as would decreases in skipjack prices. Recent technological and regulatory innovations also make Coasean-style bargaining more viable. Electronic logbook data and video-based monitoring make it simpler and less costly to collect data and monitor catches and effort. These innovations facilitate assessment for establishing fishery limits, determining historical catch as a basis for property rights assignment, and in trading fishery property rights. Similarly, the increased availability of less-costly and more accurate methods for tracking fishing activity in near real time, for example through automatic identification system (AIS) tracking algorithms (e.g. Global Fishing Watch, Kroodsma et al., 2018) and vessel monitoring systems (VMS) lower the costs of establishing and enforcing property rights, such as spatial property rights (Costello and Ovando 2019). 


\section{CONCLUSIONS}

Our objective is to reintroduce Coasean approaches to marine resource management. Although outlined in 1960, they have received less consideration than their potential value warrants. Addition of Coasean exchange to the list of potential policy interventions provides opportunities for characterizing and implementing conservation improvements in a timelier, less costly, less antagonistic, and hence, more effective manner. The result can be good for the resource, for the humans who must change behavior and bear costs in order to protect it, and for society as a whole. ${ }^{19}$

Fisheries often are presented as a canonical case of a common-pool resource, limiting the potential of Coasean bargaining and justifying standard, centralized Pigouvian-style controls. As we have noted, however, while these measures can be successful from biological perspective (Hilborn and Ovando 2014; Hilborn et al. 2020), they may not pass standard cost-benefit analyses.

When considering conservation options, a clear baseline for comparison across feasible alternatives is critical (Demsetz 1967). All policy options will be second best relative to theoretical, optimal management, and involve transaction costs. Depending on the intervention chosen, transaction costs will include those often associated with the bargaining costs in Coasean exchange. They also, however, include lobby expenses and the costs of negotiation among regulators, conservation advocates, and user groups, as well as the costs of setting, implementing, and enforcing resource-use restrictions (D. W. Allen 2000). These latter costs will be influenced by the intervention chosen and the level of trust among all

\footnotetext{
${ }^{19}$ An example of a mixed history of success, conflict, and on-going uncertainty of outcomes, is provided in the chapters included in (Fitzsimons and Wescott 2016).
} 
groups involved with it. It is not obvious, ex ante which approach, a Coasean strategy or alternative

interventions, entails the higher overall transaction costs, relative to the baseline of business as usual. ${ }^{20}$

A mechanism for exchange is key for Coasean bargaining to occur, typically a property right of some type. Hence open-access fisheries or those with limited ability to enforce exclusivity are challenging for any conservation effort. But given the wide range of world fisheries, there are other, more promising opportunities; there is a continuum from open access to formal property rights. As Ostrom (1990) discussed, small-scale community-based, controlled-access fisheries can provide a framework. Negotiations can be between community leaders and advocates, with individual rights defined and enforced within the community. Cooperative-managed fisheries offer yet another setting where bargaining can occur between advocates and cooperative members who have defined positions within the organization (Ovando et al. 2013).

Finally, some $20 \%$ of global marine fisheries capture comes from fisheries that are already managed under rights-based fishery management (RBFM). In the United States 78 fisheries making up $37 \%$ of US capture are managed under individual transferable quotas (ITQs) (Costello and Ovando 2019; Environmental Defense Fund 2020). Although regulatory constraints would prohibit setting of total allowable catches (TAC) through Coasean exchange in many of these fisheries, such RBFM programs could provide a platform for conservation

\footnotetext{
${ }^{20}$ There are other sources of cost, as well, that would determine the regulatory option selected, including information costs about the responses of resource to be protected as well as the impacts on existing resource users from controls.
} 
interests to negotiate TAC or effort reductions and the relative distribution of benefits and costs in the manner discussed here (similar to the U.S. West Coast groundfish fishing permits purchased by The Nature Conservancy in 2007, as described in Gleason et al, 2013). Alternatively, competing fleets, for example vessels targeting a lucrative species for a highend market and vessels that incidentally catch that species in pursuit of another high-volume product, could conceivably enter into Coasean bargaining to negotiate mutually beneficial reductions in incidental catch.

Even though there are no formal ITQs in the WCPO tuna fishery, there are VDS licenses where vessel owners have historical FAD use that could be grandfathered as a means of exchange. Coasean bargaining determines both the conservation goal selected as well as the distribution of costs and benefits associated with it. In the case of bigeye tuna, where areas are large with many heterogeneous fishing groups, a consensus on Pigouvianstyle regulation is unlikely absent a crisis involving multiple species and jurisdictions, as evidenced by the lack of sufficient reductions in bigeye fishing mortality during the period of perceived overfishing. A voluntary Coasean approach does not require a crisis, nor does it require general consensus. Using the existing institutional framework and assignment of related tradable rights based on historical FAD use, purse-seine vessel owners and conservation groups can enter into the proposed Coasean exchange for FAD reduction whenever new fish stock, ecosystem, and market information appears.

As Coase (1960) stated, the selection of the response to the problem of social cost depends upon a weighing of the costs and benefits of each approach. Given the diversity of challenges facing global fisheries, adding Coasean strategies to the set of tools utilized in 
fisheries management could extend the set of fisheries around the world for whom Pigouvian methods may be untenable or unsuccessful. 


\section{REFERENCES}

Allen, D.W. 2000. "Transaction Costs." In Encyclopedia of Law and Economics, edited by B Bouckaert and G De Geest, Volume 1. The History and Methodology of Law and Economics:893-926. Cheltenham: Edward Elgar.

Allen, Robin, James A. Joseph, and Dale Squires. 2010. Conservation and Management of Transnational Tuna Fisheries. John Wiley \& Sons.

Ayres, Andrew B., Eric C. Edwards, and Gary D. Libecap. 2018. "How Transaction Costs Obstruct Collective Action: The Case of California's Groundwater." Journal of Environmental Economics and Management 91 (September): 46-65. https://doi.org/10.1016/j.jeem.2018.07.001.

Bailey, Megan, U. Rashid Sumaila, Steven JD Martell, and others. 2013. "Can Cooperative Management of Tuna Fisheries in the Western Pacific Solve the Growth Overfishing Problem." Strategic Behavior and the Environment 3 (1-2): 31-66.

Baranov, T. I. 1918. "On the Question of the Biological Basis of Fisheries. Nauchnyi Issledovatelskii Ikhtiologicheskii Institut Isvestia 1 (1): 81-128." Reports from the Division of Fish Management and Scientific Study of the Fishing Industry.](English Translation by WE Ricker, 1945. Mimeographed.).

Bell, J, J Peacey, and K Stokes. 2015. "Reducing Mortality of Bigeye Tuna during PurseSeine Fishing: A Research Agenda." Arlington, USA: Conservation International.

Bernadett, Lauren D. 2014. "The Parties to the Nauru Agreement's Vessel Day Scheme: Accounting for the Rare Success of an International Agreement." Chicago-Kent Journal of International and Comparative Law 14: 105.

Breiman, Leo. 2001. "Random Forests." Machine Learning 45 (1): 5-32. https://doi.org/10.1023/A:1010933404324.

Coase, R. H. 1960. "The Problem of Social Costs." Journal of Law \& Economics 3: 1.

Costello, Christopher, and Corbett A. Grainger. 2018. "Property Rights, Regulatory Capture, and Exploitation of Natural Resources." Journal of the Association of Environmental and Resource Economists 5 (2): 441-79. https://doi.org/10.1086/695612.

Costello, Christopher, and Daniel Ovando. 2019. "Status, Institutions, and Prospects for Global Capture Fisheries." Annual Review of Environment and Resources 44 (1): 177200. https://doi.org/10.1146/annurev-environ-101718-033310.

Dagorn, Laurent, Kim N. Holland, Victor Restrepo, and Gala Moreno. 2013. "Is It Good or Bad to Fish with FADs? What Are the Real Impacts of the Use of Drifting FADs on Pelagic Marine Ecosystems?" Fish and Fisheries 14 (3): 391-415. https://doi.org/10.1111/j.1467-2979.2012.00478.x.

Davies, N., Simon D. Hoyle, Shelton J Harley, Adam Langley, Pierre Kleiber, and John Hampton. 2011. "Stock Assessment of Bigeye Tuna in the Western and Central Pacific Ocean." WCPFC-SC7-2011/SA-WP-02. Pohnpei, Federated States of Micronesia: WCPFC. https://www.wcpfc.int/node/2785.

Deacon, Robert T., and Dominic P. Parker. 2009. "Encumbering Harvest Rights to Protect Marine Environments: A Model of Marine Conservation Easements*." Australian Journal of Agricultural and Resource Economics 53 (1): 37-58. https://doi.org/10.1111/j.1467-8489.2007.00429.x. 
Demsetz, Harold. 1967. "Toward a Theory of Property Rights." The American Economic Review 57 (2): 347-59.

Environmental Defense Fund. 2020. "Catch Share Database." Fishery Solutions Center. 2020. http://fisherysolutionscenter.edf.org/database.

Escalle, L, S Brouwer, and G Pilling. 2018. "Estimates of the Number of FADs Active and FAD Deployments per Vessel in the WCPO." WCPFC-SC14-2018/MI-WP-10. 14th Regular Session, August: Western and Central Fisheries Commission, Scientific Committee.

FAO. 2016. "Fisheries and Aquaculture Software. FishStatJ - Software for Fishery and Aquaculture Statistical Time Series." FAO Fisheries and Aquaculture Department [online]. http://www.fao.org/fishery/.

FFA. 2017. "Tuna Development Indicators 2016." Pacific Islands Forum Fisheries Agency (FFA). https://ffa.int/tunadev_indicators.

Fitzsimons, James Andrew, and Geoff Wescott, eds. 2016. Big, Bold and Blue: Lessons from Australia's Marine Protected Areas. Clayton, South VIC, Australia: CSIRO Publishing.

Fletcher, W. J., R. E. Kearney, B. S. Wise, and W. J. Nash. 2016. "Response to Hughes et al., Critique of Our Study on the Effects of Large-Scale Closures in the GBR." Ecological Applications 26 (2): 642-45. https://doi.org/10.1890/15-1375.

Fletcher, Warrick Jeffrey, Robert E. Kearney, Brent S. Wise, and Warwick J. Nash. 2014. "Large-Scale Expansion of No-Take Closures within the Great Barrier Reef Has Not Enhanced Fishery Production." Ecological Applications, December. https://doi.org/10.1890/14-1427.1.

Ginn, William. 2020. Valuing Nature: A Handbook for Impact Investing. Island Press. Gleason, Mary, Erika M. Feller, Matt Merrifield, Stephen Copps, Rod Fujita, Michael Bell, Steve Rienecke, and Chuck Cook. 2013. "A Transactional and Collaborative Approach to Reducing Effects of Bottom Trawling." Conservation Biology 27 (3): 470-79. https://doi.org/10.1111/cobi.12041.

Gunn, John, Greg Fraser, and Brian Kimball. 2010. "Review of the Great Barrier Reef Marine Park Structural Adjustment Package." Australian Government - Department of the Environment and Energy.

Hampton, John, and David Fournier. 2001. "A Preliminary Stock Assessment Model for Bigeye Tuna in the Pacific Ocean." Working Paper BET-1. SCTB!4. Noumea, New Caledonia: Standing Committee on Tuna and Billfish.

https://spccfpstore1.blob.core.windows.net/digitallibrarydocs/files/fa/fafebc5b1385973e076fd4fa4caa46be.pdf?sv=2015-12$11 \& s r=b \& s i g=3 D N j 2 E h \% 2 F L f z m O A C j E S 2 S t h X K f w z p K p w f W C y g x W c v L o E \% 3 D \& s e=2$ 018-02-03T19\%3A18\%3A26Z\&sp=r\&rscc=public\%2C\%20maxage $\% 3 \mathrm{D} 864000 \% 2 \mathrm{C} \% 20$ maxstale\%3D86400\&rsct=application\%2Fpdf\&rscd=inline\%3B\%20filename\%3D\%22BET_ 1.pdf\%22.

Hanich, Quentin. 2012. "Distributing the Bigeye Conservation Burden in the Western and Central Pacific Fisheries." Marine Policy 36 (2): 327-32. https://doi.org/10.1016/j.marpol.2011.07.008. 
Harley, Shelton J, N. Davies, J. Hampton, and S. McKechnie. 2014. "Stock Assessment Of Bigeye Tuna In The Western And Central Pacific Ocean." WCPFC-SC10-2014/SAWP-01. Majuro, Republic of the Marshall Islands: WCPFC.

Havice, Elizabeth. 2013. "Rights-Based Management in the Western and Central Pacific Ocean Tuna Fishery: Economic and Environmental Change under the Vessel Day Scheme." Marine Policy 42 (November): 259-67.

https://doi.org/10.1016/j.marpol.2013.03.003.

Hilborn, Ray, Ricardo Oscar Amoroso, Christopher M. Anderson, Julia K. Baum, Trevor A. Branch, Christopher Costello, Carryn L. de Moor, et al. 2020. "Effective Fisheries Management Instrumental in Improving Fish Stock Status." Proceedings of the National Academy of Sciences, January. https://doi.org/10.1073/pnas.1909726116. Hilborn, Ray, and Daniel Ovando. 2014. "Reflections on the Success of Traditional Fisheries Management." ICES Journal of Marine Science 71 (5): 1040-46.

https://doi.org/10.1093/icesjms/fsu034.

Holland, Dan, Eyjolfur Gudmundsson, and John Gates. 1999. "Do Fishing Vessel Buyback

Programs Work: A Survey of the Evidence." Marine Policy 23 (1): 47-69.

https://doi.org/10.1016/S0308-597X(98)00016-5.

Holland, Daniel S., Erin Steiner, and Amanda Warlick. 2017. "Can Vessel Buybacks Pay off:

An Evaluation of an Industry Funded Fishing Vessel Buyback." Marine Policy 82

(August): 8-15. https://doi.org/10.1016/j.marpol.2017.05.002.

Hughes, T. P., D. S. Cameron, A. Chin, S. R. Connolly, J. C. Day, G. P. Jones, L. McCook, et al. 2016. "A Critique of Claims for Negative Impacts of Marine Protected Areas on Fisheries." Ecological Applications 26 (2): 637-41. https://doi.org/10.1890/15-0457.

ISC. 2016. "2016 Pacific Bluefin Tuna Stock Assessment." Pacific Bluefin Tuna Working Group Report Annex 9. Sixteenth Meeting of the International Scientific Committee on Tuna and Tuna-like Species in the North Pacific Ocean (ISC),. Sapporo, Japan: International Scientific Committee for Tuna and Tuna-Like Species in the North Pacific Ocean.

http://isc.fra.go.jp/pdf/ISC16/ISC16_Annex_09_2016_Pacific_Bluefin_Tuna_Stock_As sessment.pdf.

Juan-Jordá, Maria José, lago Mosqueira, Andrew B. Cooper, Juan Freire, and Nicholas K. Dulvy. 2011. "Global Population Trajectories of Tunas and Their Relatives."

Proceedings of the National Academy of Sciences 108 (51): 20650-55.

https://doi.org/10.1073/pnas.1107743108.

Kawamoto, Taro, and Akira Nakamae. 2017. "Catch Trend of Bigeye Tuna Thunnus Obesus by Purse Seine Using Fish Aggregating Devices, by Flag States and Area of Operation in Tropical Regions of the Western and Central Pacific Ocean." Fisheries Science 83 (2): 161-70. https://doi.org/10.1007/s12562-016-1047-z.

Kotchen, Matthew J, and Nicholas E Burger. 2007. "Should We Drill in the Arctic National Wildlife Refuge? An Economic Perspective." Working Paper 13211. National Bureau of Economic Research. https://doi.org/10.3386/w13211.

Kroodsma, David A., Juan Mayorga, Timothy Hochberg, Nathan A. Miller, Kristina Boerder, Francesco Ferretti, Alex Wilson, et al. 2018. "Tracking the Global Footprint of Fisheries." Science 359 (6378): 904-8. https://doi.org/10.1126/science.aao5646. 
Kuhn, Max, and Davis Vaughan. 2020. Parsnip: A Common API to Modeling and Analysis

Functions (version R package version 0.1.3). https://CRAN.R-

project.org/package=parsnip.

Libecap, Gary D. 2007. "The Assignment of Property Rights on the Western Frontier:

Lessons for Contemporary Environmental and Resource Policy." The Journal of

Economic History 67 (2): 257-91. https://doi.org/10.1017/S0022050707000101.

McCook, Laurence J., Tony Ayling, Mike Cappo, J. Howard Choat, Richard D. Evans, Debora

M. De Freitas, Michelle Heupel, et al. 2010. "Adaptive Management of the Great

Barrier Reef: A Globally Significant Demonstration of the Benefits of Networks of

Marine Reserves." Proceedings of the National Academy of Sciences 107 (43):

18278-85. https://doi.org/10.1073/pnas.0909335107.

McKechnie, S., G. Pilling, and J. Hampton. 2017. "Stock Assessment of Bigeye Tuna in the

Western and Central Pacific Ocean." Rarotonga, Cook Islands: Western and Central

Pacific Fisheries Commission, Scientific Committe, Thirteenth Regular Session.

Medema, Steven G. 2014. "The Curious Treatment of the Coase Theorem in the

Environmental Economics Literature, 1960-1979." Review of Environmental

Economics and Policy 8 (1): 39-57. https://doi.org/10.1093/reep/ret020.

O'Connor, Mary Catherine. 2016. "Off the Hook: Can a New Study in the Pacific Reel in

Unsustainable Fishing?" The Guardian, May 1, 2016, sec. Guardian Sustainable

Business. https://www.theguardian.com/sustainable-business/2016/may/01/palausustainable-fishing-protect-endangered-marine-life.

Ostrom, Elinor. 1990. Governing the Commons: The Evolution of Institutions for Collective Action. Cambridge University Press.

Ovando, Daniel A., Robert T. Deacon, Sarah E. Lester, Christopher Costello, Tonya Van Leuvan, Karlynn Mcllwain, Kent C. Strauss, et al. 2013. "Conservation Incentives and Collective Choices in Cooperative Fisheries." Marine Policy 37 (0): 132-40. https://doi.org/10.1016/j.marpol.2012.03.012.

Pigou, A.C. 1932. The Economics of Welfare. 4th Edition. London: Macmillian and Co.

Pons, Maite, Trevor A Branch, Michael C Melnychuk, Olaf P Jensen, Jon Brodziak, Jean M Fromentin, Shelton J Harley, et al. 2016. "Effects of Biological, Economic and Management Factors on Tuna and Billfish Stock Status." Fish and Fisheries, April, n/an/a. https://doi.org/10.1111/faf.12163.

R Core Team. 2019. R: A Language and Environment for Statistical Computing. Vienna, Austria: R Foundation for Statistical Computing. http://www.R-project.org/.

Sallee, James M. 2019. "Pigou Creates Losers: On the Implausibility of Achieving Pareto Improvements from Efficiency-Enhancing Policies." Working Paper 25831. National Bureau of Economic Research. https://doi.org/10.3386/w25831.

Sibert, John, Inna Senina, Patrick Lehodey, and John Hampton. 2012. "Shifting from Marine Reserves to Maritime Zoning for Conservation of Pacific Bigeye Tuna (Thunnus Obesus)." Proceedings of the National Academy of Sciences 109 (44): 18221-25. https://doi.org/10.1073/pnas.1209468109.

Squires, Dale. 2010. "Fisheries Buybacks: A Review and Guidelines." Fish and Fisheries 11 (4): 366-87. https://doi.org/10.1111/j.1467-2979.2010.00365.x.

Sun, Chin-Hwa Jenny, Fu-Sung Chiang, Patrice Guillotreau, Dale Squires, D. G. Webster, and Matt Owens. 2017. "Fewer Fish for Higher Profits? Price Response and Economic 
Incentives in Global Tuna Fisheries Management." Environmental and Resource Economics 66 (4): 749-64. https://doi.org/10.1007/s10640-015-9971-4.

Sun, Jie, Sean P. Cornelius, John Janssen, Kimberly A. Gray, and Adilson E. Motter. 2015. "Regularity Underlies Erratic Population Abundances in Marine Ecosystems." Journal of The Royal Society Interface 12 (107): 20150235.

https://doi.org/10.1098/rsif.2015.0235.

University of New South Wales. 2019. ScienceDaily. October 2, 2019. <www.sciencedaily.com/releases/2019/10/191002110331.htm>.

WCPFC. 2018. "Fourteenth Regular Session of the Scientific Committee Summary Report." Busan, South Korea: The Commission for the Conservation and Management of Highly Migratory Fish Stocks in the Western and Central Pacific Ocean. https://www.wcpfc.int/meeting-folders/scientific-committee.

Weitzman, Martin L. 1974. "Prices vs. Quantities." The Review of Economic Studies 41 (4): 477-91. https://doi.org/10.2307/2296698.

Williams, Peter, and C. Reid. 2018. "Overview of Tuna Fisheries in the Western and Central Pacific Ocean, Including Economic Conditions - 2017 Rev 1 (22 July 2018) | WCPFC." WCPFC-TCC14-2018-IP05. WCPFC. https://www.wcpfc.int/node/32051.

Wright, Marvin N., and Andreas Ziegler. 2017. "Ranger : A Fast Implementation of Random Forests for High Dimensional Data in C++ and R." Journal of Statistical Software 77 (1). https://doi.org/10.18637/jss.v077.i01. 
A) Vessels by Flag State on the WCPFC Record of Fishing Vessels

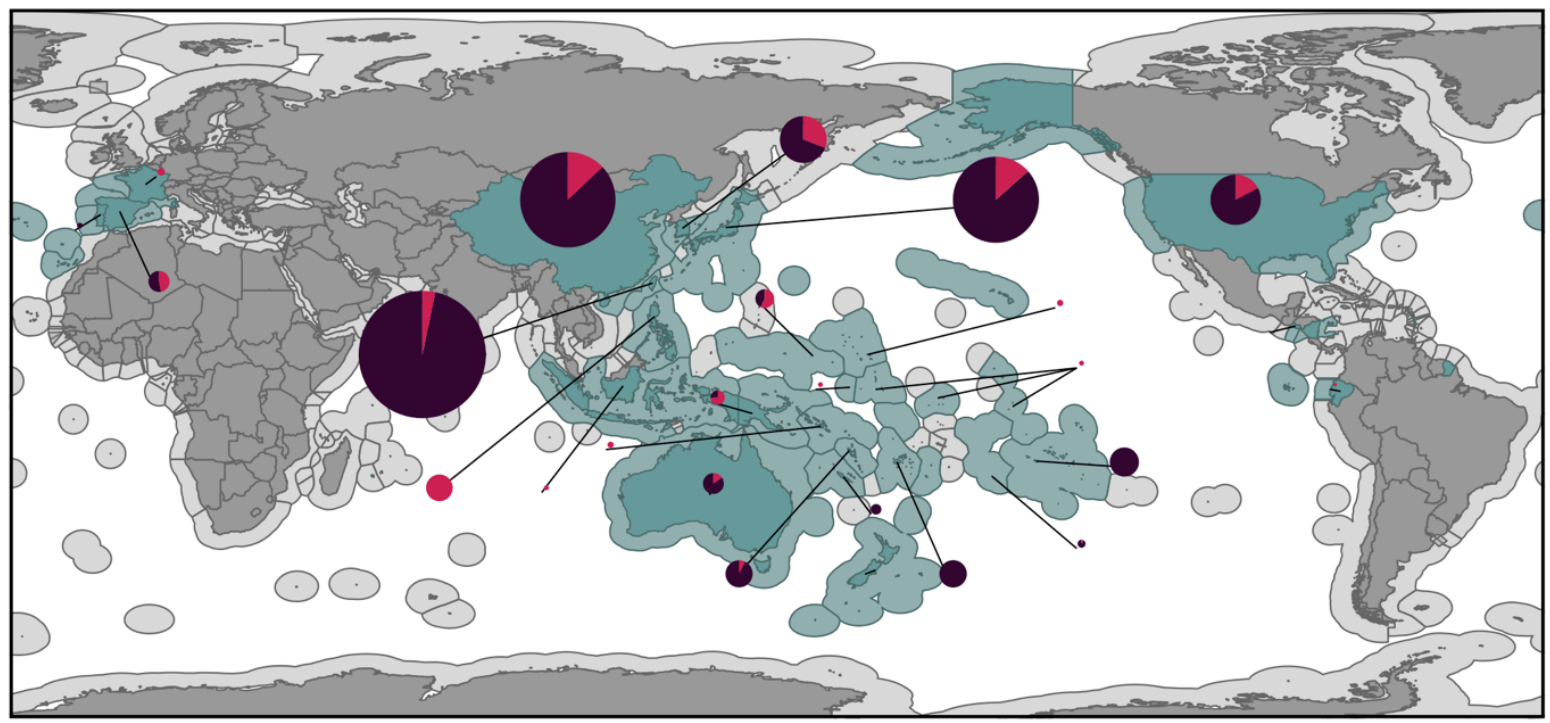

B) BET Catch by Flag State in the WCPFC Convention Area

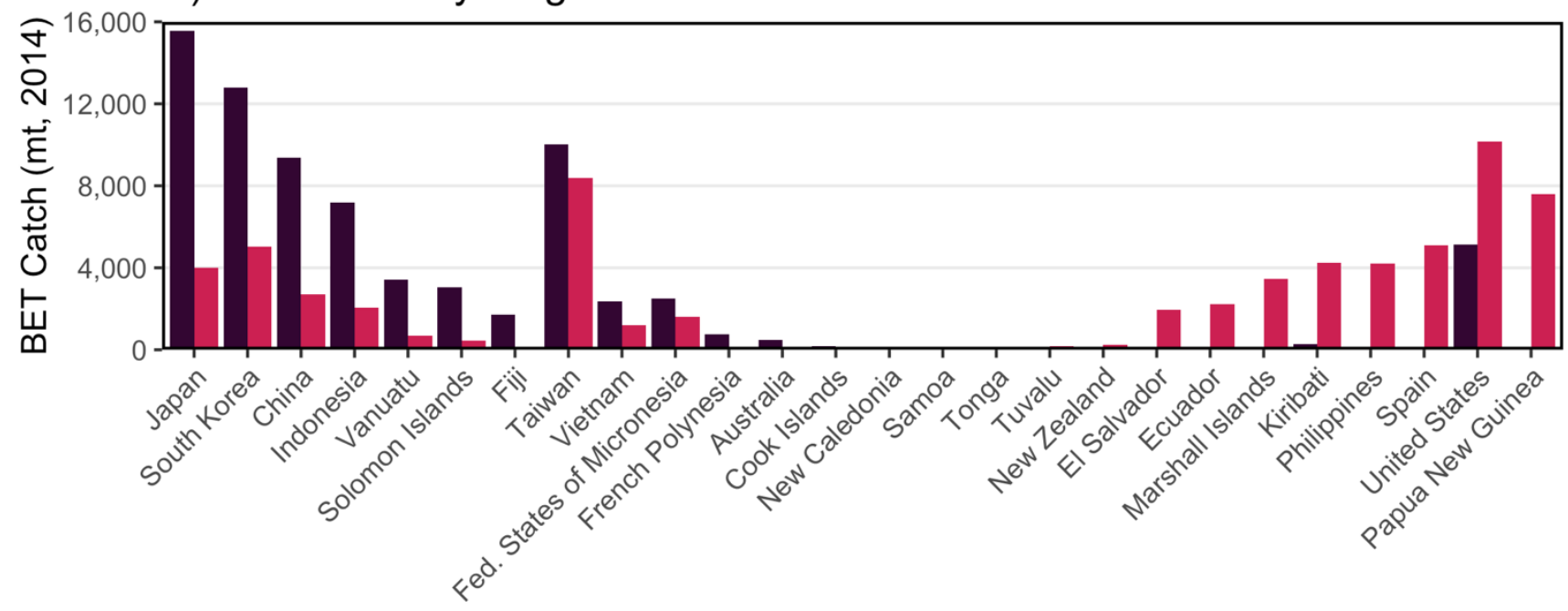

Longline $\quad$ Purse Seine

Figure 1. Panel A) shows the breakdown of vessels listed on the WCPFC Record of Fishing Vessels by gear type for each flag state. Only longline and purse seine vessels are shown, and the size of the pie is proportional to each flag state's total number of vessels of those two gear types (as of October 19, 2019). Panel B) shows the breakdown of bigeye catches by gear type for each flag state (2014). Only catches by longline and purse 
seine vessels are shown, and the bars are ordered based on the difference between longline and purse seine catches. 


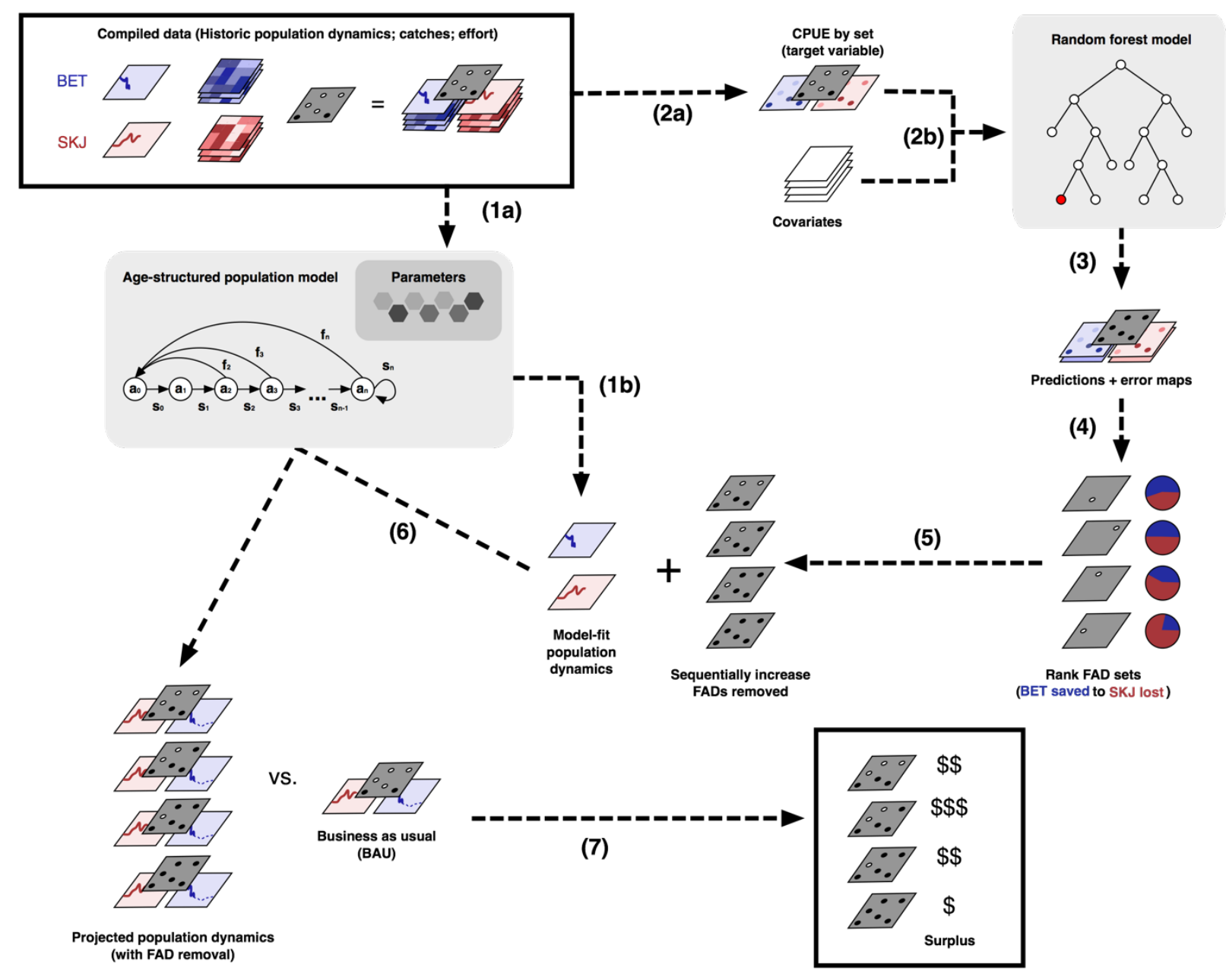

Figure 2. Schematic of the process used to estimate effects of fish-aggregating device (FAD) removal on bigeye and skipjack tuna fishing revenues. 

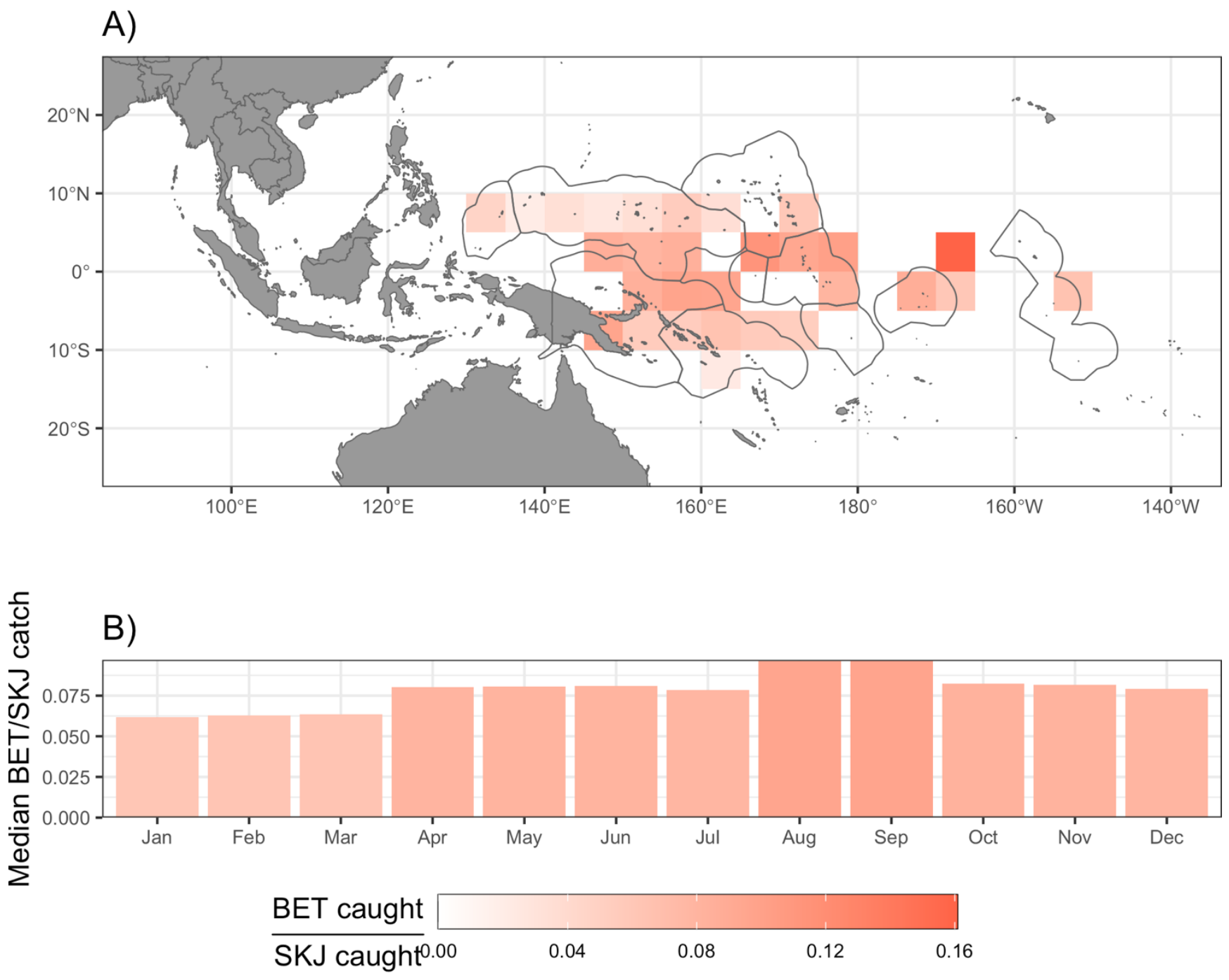

Figure 3. Median observed ratios of bigeye (BET) and skipjack (SKJ) caught by FAD associated purse seine fishing by A) latitude/longitude and B) month (2000 - 2014). 


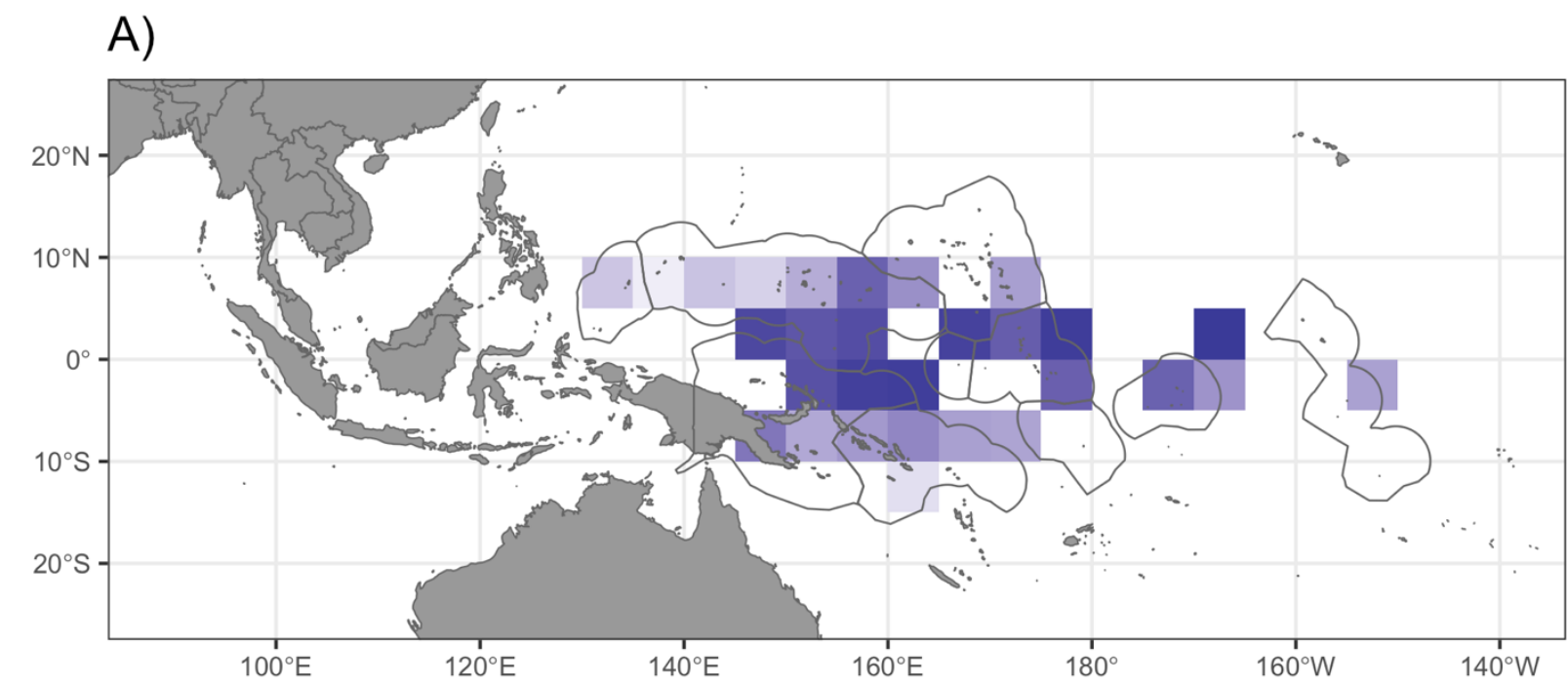

B)
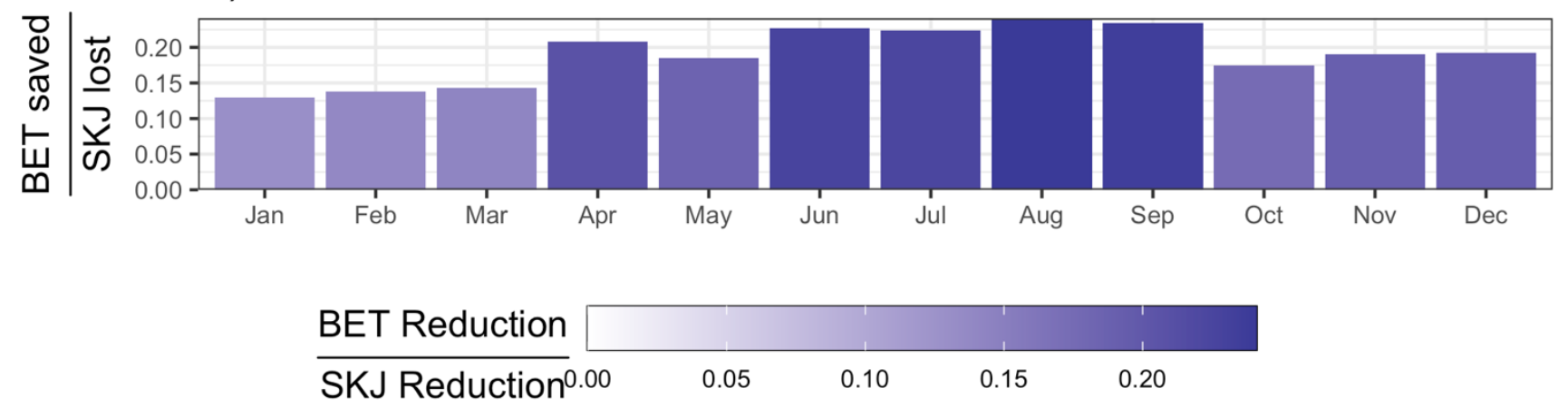

Figure 4. Median predicted ratios of reduction in bigeye (BET) and skipjack (SKJ) CPUE resulting from moving from FAD to free-school purse seine fishing by A) latitude/longitude and B) month (2000 - 2014). 
A)

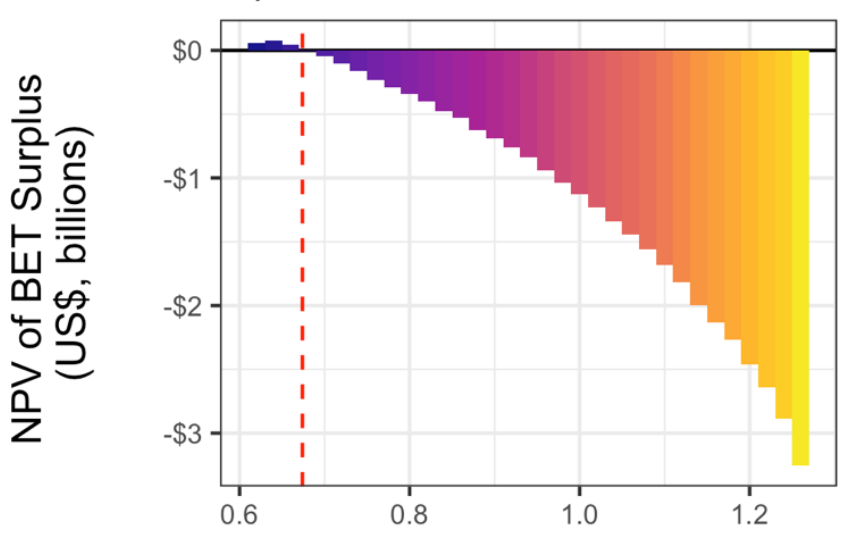

C)

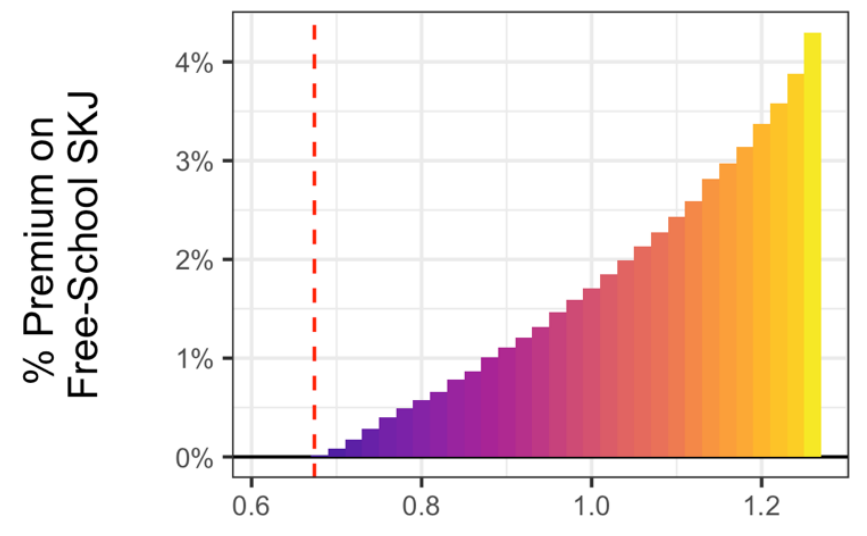

B)

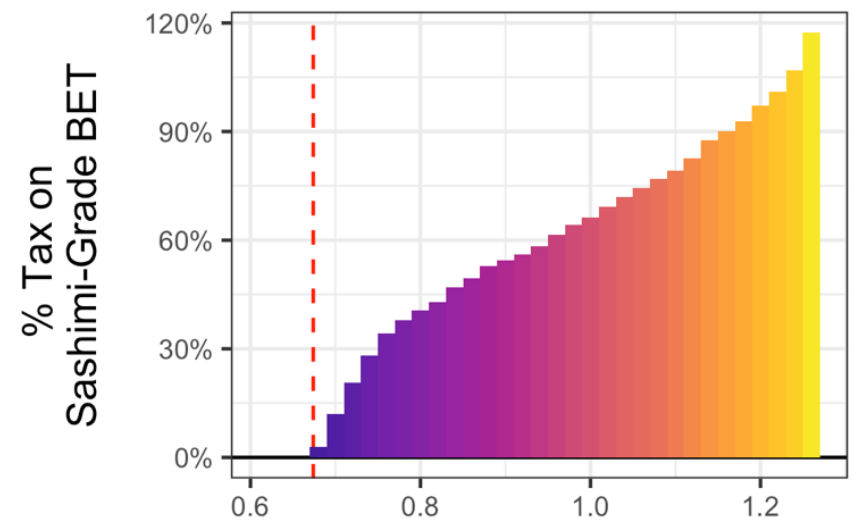

D)

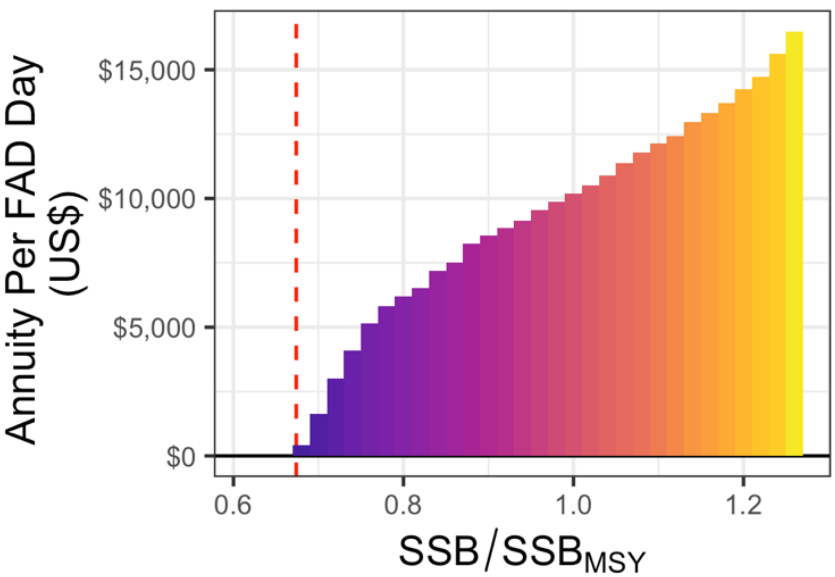

$\%$ of FAD Days Purchased

Figure 5. Projected Economic Tradeoffs Associated with Conservation Outcomes Achieved as a Function of Different FAD removals. The $X$-axis in all panels shows projected equilibrium SSB/SSBMSY as a function of removing increasing percentages of FADs from the WCPO (color scale of bars). Fisheries management generally has an objective of SSB/SSBmsY values near 1. On the y-axes, Panel (A) shows the projected net present value of the bigeye surplus (assuming a discount rate of 10\%). Panel (B) shows the estimated \% tax on sashimi grade bigeye in Japanese markets that would be required to offset losses in the skipjack revenues as FAD use is reduced and thereby achieve a benefit-cost ratio of 1 . Panel (C) shows alternatively, the estimated 
price premium on canned and labeled free-school skipjack to achieve the same tradeoff balance. Panel (D) shows the estimated associated annual annuity payments per FAD day required for compensating the loss in skipjack harvest as FAD reductions are increased for different of SSB/SSBMSY objectives. 
Table 1. NPV of revenue benefits (increases in bigeye catch) and revenue costs (losses in skipjack catch) (costs and benefits in USD billions) and equilibrium SSB/SSBMSY resulting from incremental increases in percent of VDS FAD days removed

\begin{tabular}{|c|c|c|c|c|}
\hline Percent of FADs Removed & SSB/SSB $_{M S Y}$ & Benefits & Costs & Surplus \\
\hline $15 \%$ & 0.6 & $\$ 0.21$ & $\$ 0.17$ & $\$ 0.04$ \\
\hline $26 \%$ & 0.7 & $\$ 0.63$ & $\$ 0.82$ & $\$-0.19$ \\
\hline $39 \%$ & 0.8 & $\$ 1$ & $\$ 1.5$ & $\$-0.5$ \\
\hline $53 \%$ & 0.9 & $\$ 1.5$ & $\$ 2.4$ & $\$-0.9$ \\
\hline $67 \%$ & 1.0 & $\$ 1.9$ & $\$ 3.3$ & $\$-1.4$ \\
\hline $85 \%$ & 1.1 & $\$ 2.3$ & $\$ 4.4$ & $\$-2.1$ \\
\hline $100 \%$ & 1.2 & $\$ 2.7$ & $\$ 5.7$ & $\$-3$ \\
\hline
\end{tabular}




\section{ONLINE APPENDIX}

\section{COMPUTATIONAL ENVIRONMENT}

The code underlying this paper requires several different types of analysis, and associated packages. All analyses were performed in $R$ (R Core Team 2019). Many packages were utilized, in particular TMB (Template Model Builder, Kristensen et al. 2016), ranger (Wright and Ziegler 2017), and (Kuhn and Vaughan 2020). Materials and data needed to reproduce all results can be found at https://github.com/DanOvando/coasean-tuna .

\section{POPULATION MODEL}

The tuna complex in the Western Central Pacific Ocean (WCPO) is a highly studied group of species. Formal stock assessments exist for both of the species included in this study (bigeye tuna, Thunnus obesus, and skipjack tuna, Katsuwonus pelamis). Given the extensive modeling already present for these species, why create our own population model? The latest stock assessment models for bigeye and skipjack consist of 32 and 23 "fleets" (defined by gear type, region, and nationality) and 9 and 5 assessment regions respectively (McKechnie et al. 2016; 2017). However, publicly available FAD associated data is only available at a coarser resolution, reporting only at the $5^{\circ} \times 5^{\circ}$ latitude/longitude resolution. As such, we have no clear way of assigning changes in FAD use to the resolution of the fleets used in the stock assessment models. The stock assessment model also contains many features (such as movement rates) which while critical for the management of the species are not vital for the strategic analysis presented here. A tactical model designed to actually implement the methods discussed here would certainly require a model more in line with the 
complexity of the stock assessment models. However, our simplified model allows us to capture critical features of the stock, including broad differences in fleet dynamics and selectivities, at a resolution compatible with the needs of the analysis and the available data. The population model is single-species and age-structured, with Beverton-Holt style recruitment dynamics. Numbers at time $t$ for age a $\left(n_{t, a}\right)$ are given by

$$
n_{t, a}= \begin{cases}=B H\left(s s b_{t-1}\right) & \text { if } a=1 \\ =n_{t-1, a-1} e^{-\left(m_{a}+f_{t} * s_{a-1}\right)}, & \text { if } 1<a<\max (\text { age }) \\ =n_{t-1, a} e^{-\left(m_{a}+f_{t} * s_{a}\right)}+n_{t-1, a-1} e^{-\left(m_{a}+f_{t}^{\left.* * s_{a-1}\right)},\right.}, & \text { if } a=\max (a)\end{cases}
$$

where $B H$ is the Beverton-Holt recruitment function, $s s b_{t-1}$ is spawning-stock-biomass at time $t-1, m_{a}$ is natural mortality at age $a, f_{t}$ is fishing mortality at time $t$, and $s_{a}$ is selectivity at age a.

Natural mortality at age for bigeye was taken from the 2014 stock assessment (Fig. A1, Harley et al. 2014).

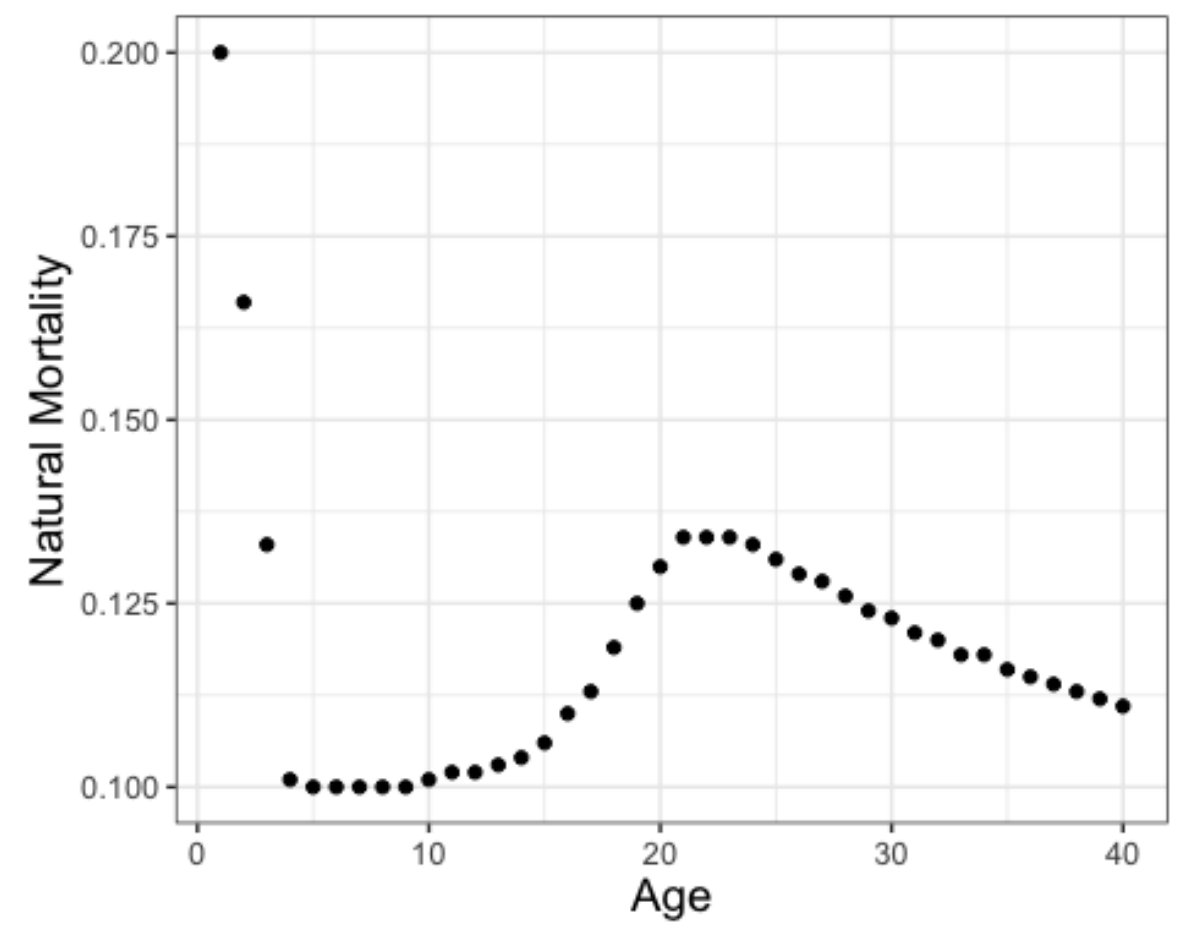


Figure A1. Natural mortality at age for bigeye tuna, from Harley et al. (2014).

Spawning stock biomass $\left(s s b_{t}\right)$ is calculated by converting age to mean length $l_{a}$, calculating weight at age $w_{a}$ and maturity at age $m_{a}$, and then calculating spawning stock biomass as the sum of spawning potential at age in a given time step.

$$
l_{a}=l_{\infty}\left(1-e^{-k\left(a-a_{0}\right)}\right)
$$

Where $l_{\infty}$ is the mean asymptotic length, $k$ is the von Bertalanffy growth coefficient, and $a_{0}$ is the theoretical age when $l_{a}=0$.

Weight at age $a$ is then given by

$$
w_{a}=\alpha \times l_{a}^{\beta}
$$

Where $\alpha$ scales the units of weight and $\beta$ represents the relationship between length and weight.

Maturity at age (mat $\left.{ }_{a}\right)$ was also taken from the 2014 stock assessment (Fig. A2, Harley et al. 2014), which importantly captures the concave shape of the maturity function at higher ages of bigeye tuna 


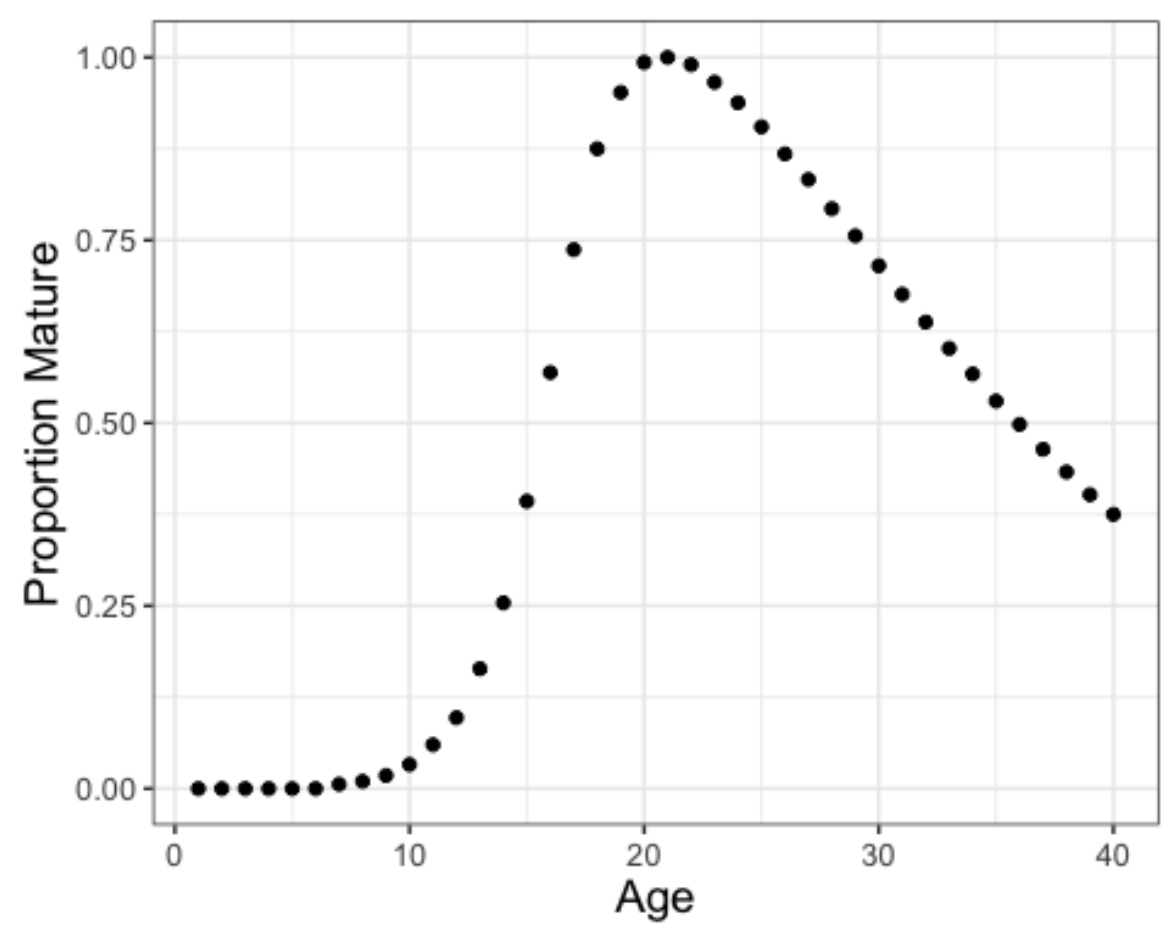

Figure A2. Mean proportion of bigeye individuals sexually mature at age, from Harley et al. (2014).

Spawning stock biomass at time $t$ is then calculated as

$$
s s b_{t}=\sum_{a=1}^{A} w_{a} m a t_{a} n_{a, t}
$$

We chose to use a Beverton-Holt recruitment function for this simulation. This is a slight deviation from the methods used in the latest bigeye stock assessments, which allow for deviation from a fixed stock-recruitment relationship to occur. Harley et al. (2014) and McKechnie et al. (2017) both assume bigeye recruitment to have a weak relationship with spawning potential via a Beverton-Holt function with a fixed value of steepness, $h$, but allow deviations from this relationship to occur as such as relationship is not clearly defined for 
most tuna species. Nonetheless, all recent stock assessments in the WCPO have incorporated a Beverton-Holt relationship for the purposes of undertaking yield analysis and population projections (on the recommendation of an independent assessment review, lanelli et al. 2012), but apply a very weak penalty for deviation from the stock-recruitment relationship so that it does not seriously bias recruitment and other model estimates.

For the Beverton-Holt equation, we first calculate $\alpha$ as

$$
\alpha=\left(s s b_{0} / r_{0}\right) \times(1-h) /(4 \times h)
$$

where $r_{0}$ is unfished recruitment (set in the model tuning process), $h$ is steepness, set to 0.8 per Harley et al. (2014), and $s s b_{0}$ is calculated analytically by calculating the SSB at equilibrium given $r_{0}$ and the other life history parameters. $\beta$ is given as

$$
\beta=(5 \times h-1) /\left(4 \times h \times r_{0}\right) .
$$

Finally, recruits are calculated by

$$
n_{a=0, t}=\frac{s s b_{t-1}}{\alpha+\left(\beta \times s s b_{t-1}\right)} .
$$

As a simplification of the 33 "fisheries" or "fleets" defined in Harley et al. (2014), we define the following five fleets fishing in the WCPO: longline fishing (LL), purse seine fishing on FADs in PNA waters (PS-FAD-PNA), purse seine fishing on FADs outside of PNA waters 
(PS-FAD), free school purse seine fishing in PNA waters (PS-PNA), and free school purse seine fishing outside of PNA waters (PS). A time series of quarterly catch and effort data from the WCPFC online data portal was allocated accordingly to each fleet. Selectivity at age for each fleet was defined as the average of that for all fleets from Harley et al. (2014) with the same gear type (LL, PS, or PS-FAD), weighted by the percentage of total catches originating from that fleet's region. Catchability by quarter was set in the model tuning process.

\section{TUNING TO STOCK ASSESSMENT}

Given these population and fleet dynamics, we now need to tune our simplified model to resemble the stock status reported in Harley et al. (2014). We could have tried to fit a new assessment model, given supplied catches, CPUE, and length composition data. However, given the complex spatial and multi-fleet nature of the original assessment, we felt it unlikely that our simplified model would reach the same conclusions as Harley et al. (2014) as to the current state of the population given only some of the same data used in the original assessment.

As such, we elected to "tune" rather than fit our model. We accomplish this by estimating an unfished recruitment, catchability by fleet and time, and an initial depletion that, given the time series of effort and selectivities by fleet, best reproduces the time series of depletion and catches by fleet reported in Harley et al. (2014).

This is, of course, a rough approximation of the model estimated in Harley et al. (2014), but it captures some of the key life history traits of bigeye tuna (including varying natural mortality and maturity at age), while allowing us to translate changes in fleet efficiency 
brought on by FAD removal directly into the operating model estimated here. In the end, since we are projecting the population forward holding fishing mortality rates constant, the most important factor is getting the most recent fishing mortality rates approximately correct,

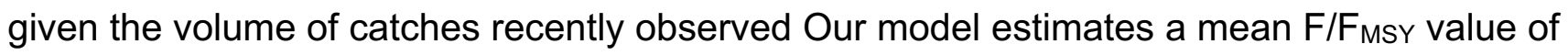
1.2 from 2008 - 2011, (Fig. A3), close to the values of 1.57 over that period reported in Harley et al. (2014).

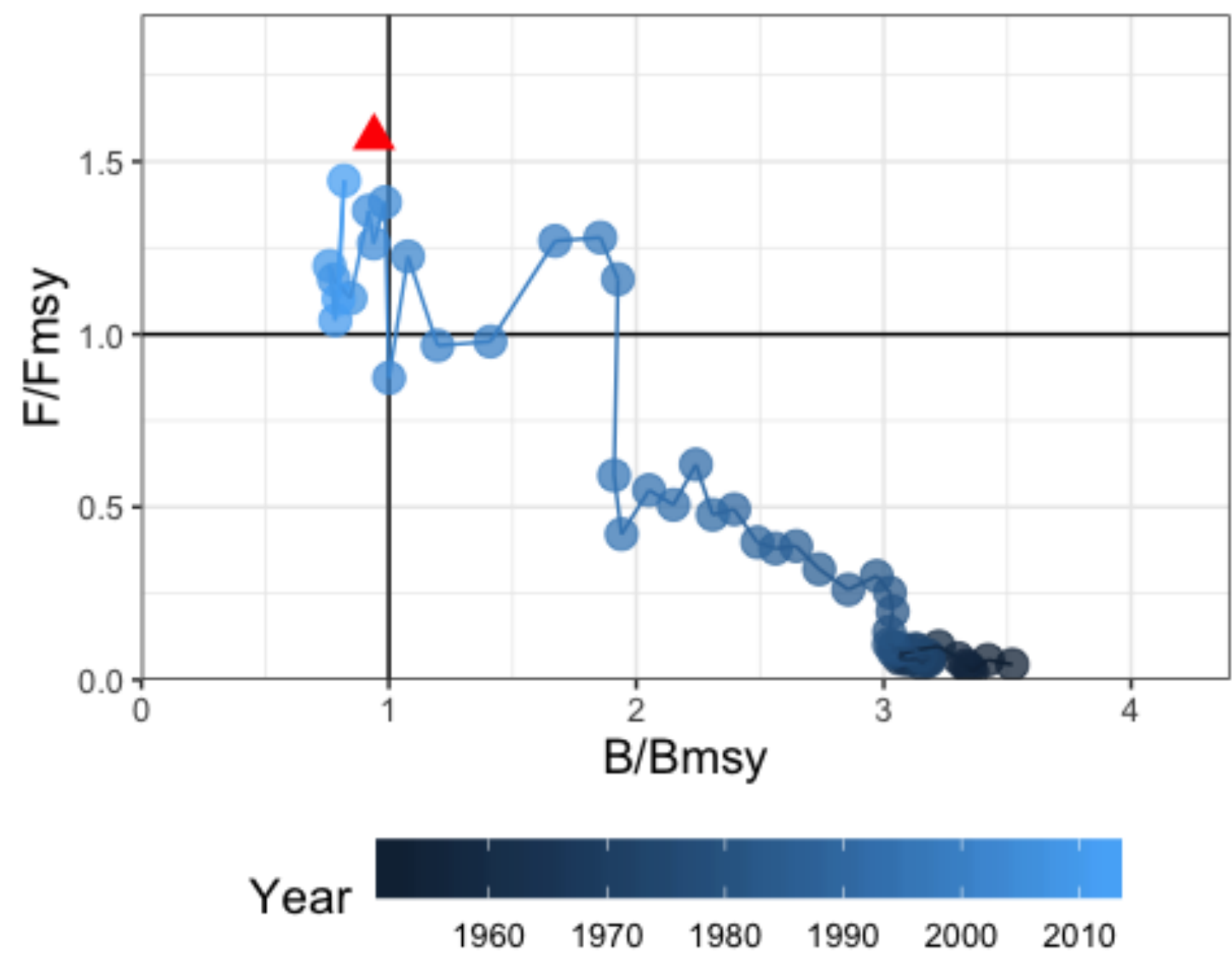

Figure A3. Tuned values of $\mathrm{B}_{\mathrm{B}} \mathrm{B}_{M Y}$ and $\mathrm{F} / \mathrm{F}_{M S Y}$ over time. Red triangle shows average $\mathrm{B} / \mathrm{B}_{M S Y}$ and $\mathrm{F} / \mathrm{F}_{M S Y}$ over the period 2008 - 2011 from Harley et al. (2014).

\section{ESTIMATING FAD EFFECTS}


Given this operating model, we then require a method of estimating the effect of FAD removal. FAD use affects many aspects of fishing operations, including search time (Lopez et al. 2014), success rates (Fonteneau et al. 2000; Suzuki et al. 2003; Miyake et al. 2010), size composition (Guillotreau et al. 2011), etc. For this simplified scenario, we focus on the effect of FAD use on CPUE.

We obtained a database of bigeye and skipjack catches and effort by space, time and gear from the WCPFC online portal (https://www.wcpfc.int/node/4648), accessed on July 17, 2017. This public domain database contains historical catch and effort data by month and by flag/quarter grouped by $5^{\circ} \times 5^{\circ}$ latitude/longitude for all tuna fisheries operating in the WCPFC Convention Area. Data points representing less than three vessels are not included in the public domain database. Importantly, this gives us information on the total catch of bigeye or skipjack, the number of days fished to obtain that catch, and covariates including the FAD type used (including if it was a free-school set), the rough location $\left(5^{\circ} \times 5^{\circ}\right.$ latitude/longitude cells), year and month. We paired these data with data on sea-surface temperature (SST) obtained from NASA Goddard Space Flight Center's Ocean Data Processing System (2014), estimated as the average SST across the $5^{\circ} \times 5^{\circ}$ cell in the year and month of a given observation of FAD fishing.

This allows us to estimate a rough model of CPUE as a function of location, year, month, sea-surface temperature, and FAD use. The goal of this model is to ask, if we were to move from FAD-associated to free-school fishing at a given observation, how would we expect CPUE to change?

We estimated this model using a random forest (Breiman 2001) implemented through the ranger package in $\mathrm{R}$. The model was trained on the years 1995 to 2008 , to isolate a 
relative modern period prior to the implementation of summer FAD closures in 2009. The training data were split into a series of assessment and analysis splits that each select a sequentially longer part of the training data to use as an assessment split, holding out the remaining time steps prior to 2009 as the analysis split. These assessment and analysis splits were used to tune relevant hyper-parameters (by selecting those that minimized root-meansquared error of the analysis splits).

Once the best hyper-parameters of the random forest were selected, we then trained the model with these hyper-parameters on the training data, and used the subsequent model to predict CPUE for the testing data of 2009 onward, which critically includes the newly implemented summer FAD closures.

The summer FAD closures provide an ideal case study on the effects of FAD removal on CPUE. Looking at the raw data, median CPUE declines sharply for both bigeye and skipjack during the FAD closures (Fig. A4). Despite not being exposed to these periods on the training data (which would allow the model to simply learn that the summer months post 2009 are associated with lower CPUEs), our model is able to capture these general dynamics. This gives us confidence that the model is able to provide a reasonable prediction of CPUE as a function of FAD type. A more tactical model would clearly need to account for complications like the effect of overall stock size on CPUE, but for our purposes the critical factor here is the relative reduction in CPUE as a function of moving from FAD to free-school fishing. To estimate this, we pulled out all the observations of FAD fishing from the data, set their fishing type to free-school, and then used our model to predict their new CPUE. This provides an estimate of the difference in CPUE with and without FAD use across space, time. 
For comparison, we only include data from 2009 onward, and only for locations that reported use of FADs in a given month prior to 2009 . This helps control for the possibility that during the FAD closures may simply move to new locations. Instead, we attempt to estimate the change in CPUE during the summer FAD closures for sites that at least prior to the FAD closures did use FADs in the summer months.

A) Bigeye

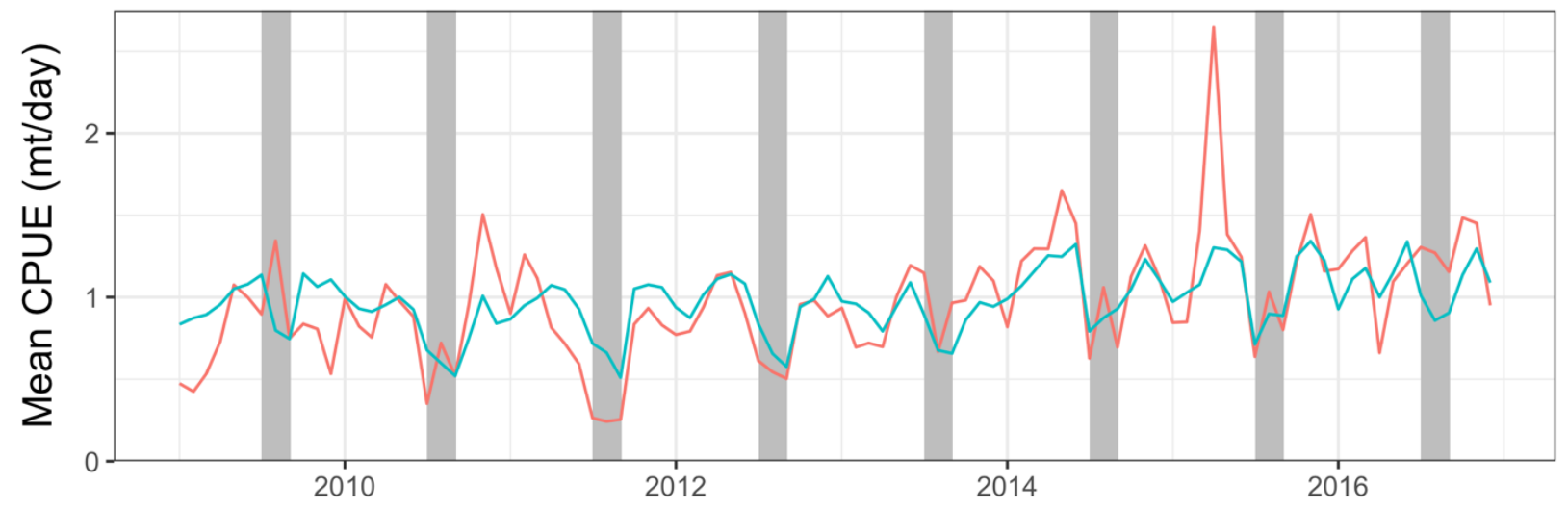

B) Skipjack

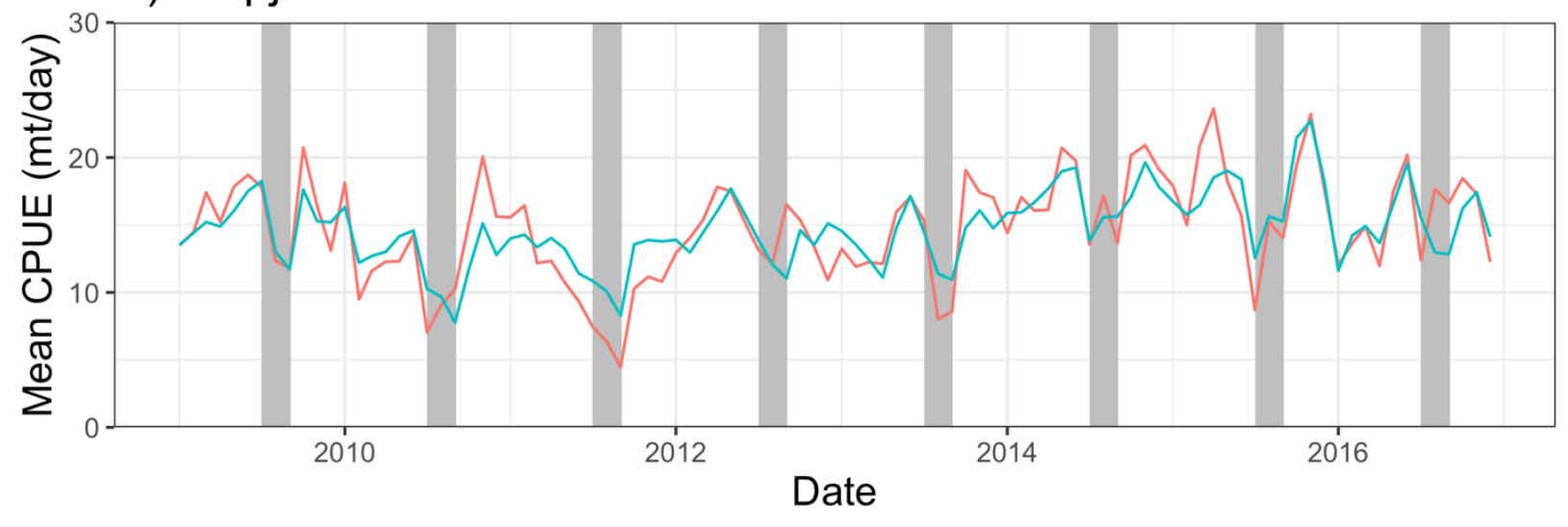

— Observed — Predicted

Figure A4. Mean observed (red) and predicted (blue) CPUE for bigeye and skipjack tuna in the WCPO since 2009. Grey bars indicate seasonal FAD closures which were omitted from the model fitting. Plotted data only include sites that used FADs pre-2009, to control for possibility of movement to different sites during the FAD closures. 
Many alternative model types were tested, including gradient boosted models, generalized linear models, and generalized additive models, all of which provide qualitatively similar but less accurate results.

Our results assume that we are able to predict CPUE on and off of FADs reasonably well into the future. As test of this assumption, we also fit our model using only pre-2009 data, and then predicted CPUE on and off FADs for both bigeye and skipjack from $2009-2016$ (Fig. A5). 


\section{A) Bigeye}

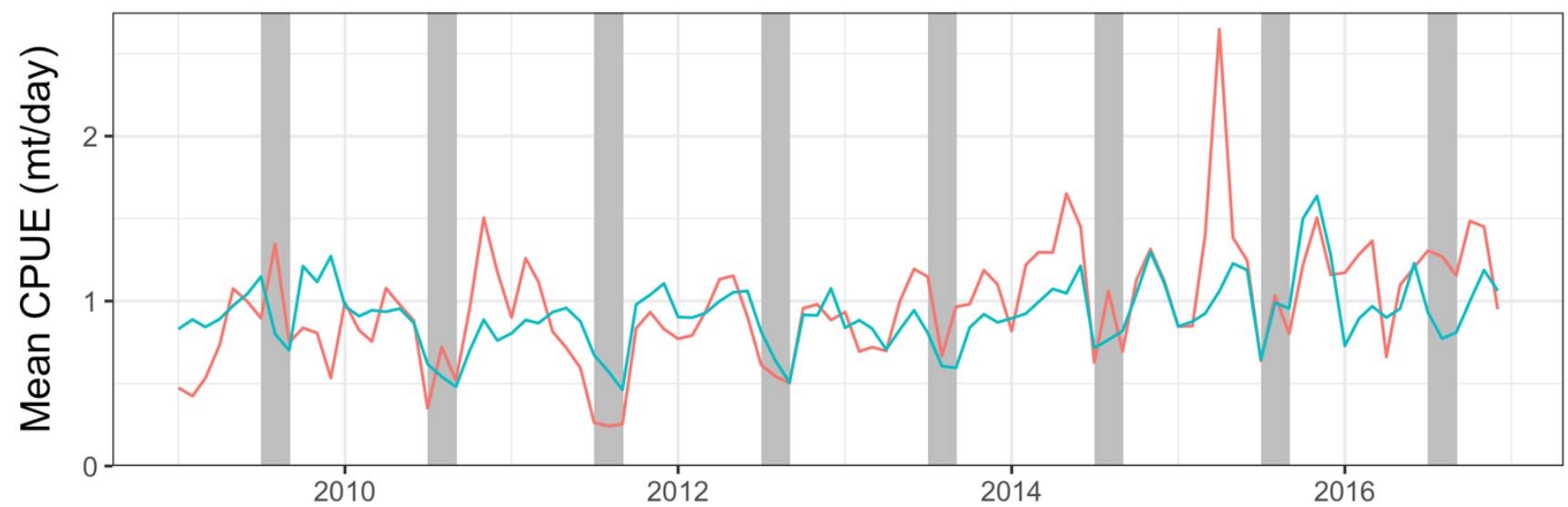

B) Skipjack

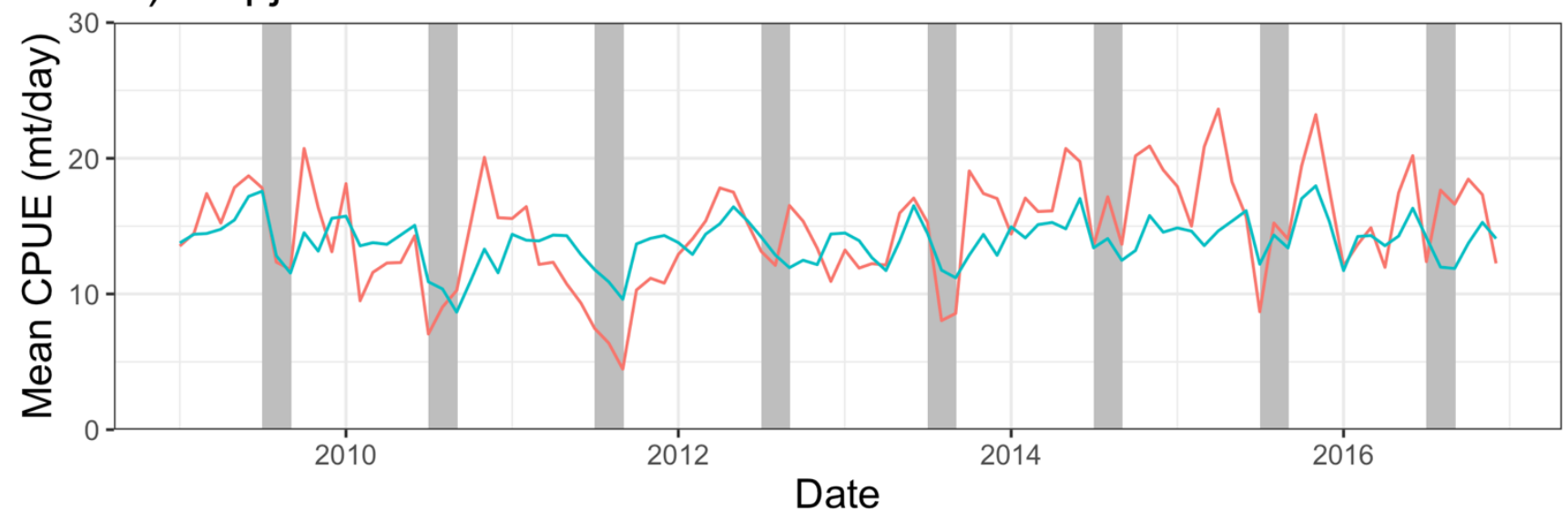

- Observed - Predicted

Figure A5. Mean observed (red) and predicted (blue) CPUE for bigeye and skipjack tuna in the WCPO since 2009. Grey bars indicate seasonal FAD closures. Predictive model was trained on pre-2009 data. Plotted data only include sites that used FADs pre-2009, to control for possibility of movement to different sites during the FAD closures.

To summarize model performance, for each year we estimate an empirical FAD affect as the ratio of CPUE during the summer FAD closures to the CPUE at the same locations when FADs are allowed. We then calculated the mean absolute percent error (MAPE) 
between this empirical measure of a FAD Effect and the FAD effect predicted by our models during periods held out from the model training (Fig. A6). For bigeye tuna, the MAPE was $32 \%$ for post-2009 period when the model was trained on pre-2009 data, and $34 \%$ for the summer FAD closures when only the summer FAD closures were held out from the model. For skipjack, the MAPE for each experiment were $16 \%$ and $21 \%$. This provides evidence that our model performs similarly when tasked with predicting future values as when "filling in the gap" of summer FAD closures (though both predictions do come with reasonable amounts of error). 


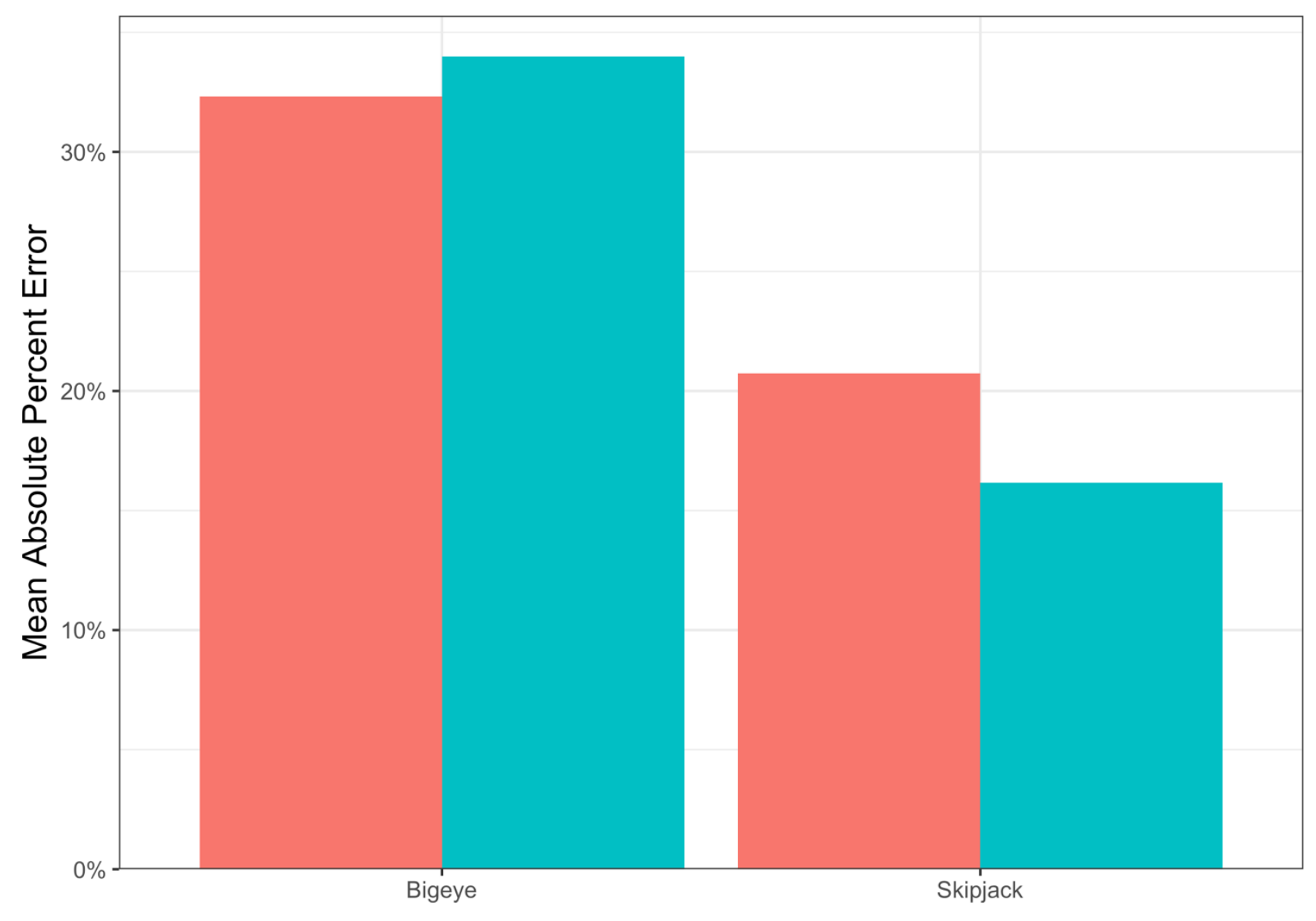

Held-Out Data _ Post 2009 Data Summer FAD Closures

Figure A6. Mean absolute percent error (MAPE) of held-out data for bigeye and skipjack. Red bars are MAPE for post-2009 data when only pre-2009 data were used for model training. Blue bars are MAPE for summer FAD closures when only data from outside the summer FAD was used. Plotted data only include sites that used FADs pre-2009, to control for possibility of movement to different sites during the FAD closures.

\section{PROJECTING FAD EFFECTS}

We used our population model together with our model of FAD effects on CPUE to estimate the effect of FAD removal on the bigeye and skipjack fishery. Critically, since our 
FAD model is estimated at the resolution of $5^{\circ} \times 5^{\circ}$ cell, month, FAD type, we are able to represent the wide heterogeneity in FAD effects on bigeye and skipjack CPUE.

Our objective is to estimate the gains in the bigeye fishery and losses in the skipjack fishery resulting from FAD removal. Selecting only FAD associated observations, for each observation $i$ at the resolution of FAD type, latitude, longitude, year, and month, we first calculated the expected change in catch $\Delta$ for both species, $s$ (skipjack or bigeye), resulting from moving from FAD to free-school (free) fishing

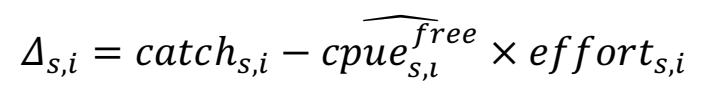

For each observation $i$, we can then calculate the difference in the expected change in bigeye and skipjack catch as a function of FAD removal, freeschool, as

$$
\text { freeshool }_{i}=\Delta_{s=\text { bigeye }, i}-\Delta_{s=\text { skipjack }, i}
$$

An observation with a very large value of freeschool means that our model estimates that moving from FAD to freeschool fishing at observation $i$ would reduce bigeye catch substantially more than it would reduce skipjack catch, and vice versa. Note that clearly in some instances our model estimates that moving from FAD to freeschool will actually increase bigeye or skipjack catch. We consider this outcome to be somewhat unlikely. It is possible that captains are trading off the increased certainty of FAD catches with potential catch volume, but we believe a simpler explanation is that the model is incorrect in those circumstances. As such, and to be conservative as to the magnitude of the potential benefits 
of FAD removal, we only include locations $i$ that estimate reductions in both bigeye and skipjack CPUE as a function of moving to free-school fishing. We re-ran the analysis including all observations (including those which the model projected freeschool fishing to positively affect catches).

For each observation $i$, we then calculated the mean freeschool effect and $\Delta$ from 2009-2016, giving us the mean values of $\Delta$ and freeschool at each location and month over that time period. We then arrange the resulting predictions in descending order of freeschool, so that the first FADs moved through our proposed "bargain" to freeschool fishing are those we would expect to provide the greatest reduction in bigeye and the least reduction in skipjack.

From the perspective of the population though, the key question is not only the expected change in catches today resulting from moving to freeschool fishing, but the longterm effects of this change on the population. Moving sequentially through the potential instances of FAD removal, we estimate the effect of changing $n$ instances of FAD fishing to freeschool fishing as follows. To try and simplify this process somewhat, we only project the effect of FAD removal on the bigeye population. We make this choice because the skipjack population is estimated to be quite healthy with relatively low levels of fishing mortality. As such, we assume that both current catches of skipjack, and reduced catches of skipjack resulting from moving to free-school fishing, will persist into the future.

For bigeye, we need to translate changes in catches stemming from the free-school shift into changes in fishing mortality rates. For each fleet and quarter, we pull out the total reported bigeye catches in 2016. We then adjust these catches as a function of switching $n$ instances of FAD fishing to free-school fishing. The new catch by the purse-seine FAD fleet in 
a quarter is equal to the current purse-seine FAD catches in that quarter minus the total expected reduction in bigeye catch from switching to $n$ observations of FADs to freeschool fishing $\left(\sum_{i=1}^{n} \Delta_{s=b i g e y e, i}\right)$. Remember though that the assumption of this bargain is that fishing isn't removed, but instead switched to free-school purse-seine fishing. As such, we calculate the new catch in the free-school purse-seine fleet in a given quarter as the observed catch by that fleet in that quarter in the most recent year, plus the total amount of bigeye predicted by

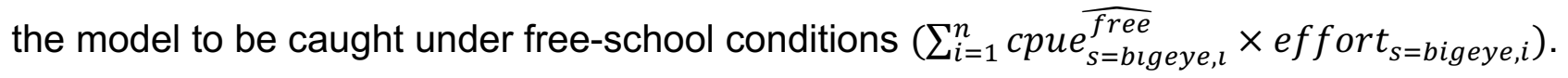

This step gives us new expected catches by fleet, reflecting the switching of $n$ FADs. From there, we use the Baranov equation (Baranov 1918) to estimate the fishing mortality rate that, given the estimates of the population in the most recent time step derived from the model tuning, would produce these new expected catches. This more or less translates to, if FAD associated purse seine catches were expected to decrease by $5 \%$, FAD associated fishing mortality rates will decrease by approximately $5 \%$. After adjusting the fishing mortality rates of the free-school and FAD associated purse-seine fleets accordingly, we then project the population forward in time, holding these updated fishing mortality rates constant. The resulting bigeye population trajectory is then calculated, considering these new fishing mortality rates, and importantly the difference in selectivity of the fleets.

This projection gives us a vector of new expected bigeye catches by fleet. Under the idea of our bargain, the proposed "beneficiaries" is the targeted longline bigeye fleet. We calculate the benefits accrued to the longline fleet as the net present value (assuming a $5 \%$ discount rate) of the difference in longline bigeye catches under business as usual (i.e. assuming no FADs are switched to free-school) and under incrementally greater amounts of FAD removal $\left(\sum_{t=0}^{T}\left(l l c a t c h_{t}^{B A U}-\operatorname{llcatch}_{t}^{n}\right)(1+.05)^{-t}\right)$. 
Those being the "benefits", the costs are then the expected losses to the purse-seine fleet. Since we are not projecting the skipjack population, we assume that the total amount of skipjack lose (that must be compensated for) is $\sum_{i=1}^{n} \Delta_{s=s k i p j a c k, i}$ in each timestep, plus $\sum_{i=1}^{n} \Delta_{s=b i g e y e, i}$ to account for the value that the purse-seine fleet would have obtained from the incidental bigeye catch. We then calculate the net present value of these costs. The surplus generated by the bargain is then simply the difference in the NPV of the benefits to the longline fleet, minus the NPV of the costs to the purse-seine fleet.

\section{Estimating Alternative SOURCES OF BenEfits}

As shown in Fig. 4, while our exercise suggests that complete removal of FADs from the WCPO could have substantial positive impacts on the bigeye stock, the direct fishery benefits of these gains are quickly dwarfed by the direct fishery losses. As an exercise then, we considered what the magnitude of several alternative strategies for offsetting these losses would have to be. For the first, we calculate the tax on longline caught bigeye tuna (sashimigrade bigeye) that would be required to make up the deficit to the purse-seine fleet. For removal of $n$ FADs, this is simply

$$
\operatorname{tax}_{n}=p_{\text {sashimi }} \times \frac{n p v_{n}^{\text {costs }}-n p v_{n}^{\text {benefits }}}{n p v_{n}^{\text {benefits }}}
$$

where $p_{\text {sashimi }}$ is the current price of sashimi grade bigeye. Put simply, we calculate the percentage increase in net present value needed in order for costs to equal benefits, and augment price accordingly. This is a large simplification, since ideally, we would account for 
the effects that this tax would have on demand, but it serves as a useful illustration of the general magnitude of the price increase required (Fig. 5B).

We also calculate the percent price premium that would need to be paid for "FAD-free" canned skipjack tuna in order for costs to equal benefits. This is simply the percentage increase in the value of canned skipjack tuna that would be required to offset the losses incurred to the purse-seine fleet (accounting for any payments that the longline fleet might already be making) (Fig. 5C)

Lastly, we consider what the conservation payments per FAD day would have to be in order for the NPV of costs to equal the NPV of benefits. We calculated this as the as annual annuity payment per FAD day such that benefits equal costs (Fig. 5D).

\section{ONLINE APPENDIX REFERENCES}

Baranov, T.I. 1918. On the question of the biological basis of fisheries. Reports from the Division of Fish Management and Scientific Study of the Fishing Industry, 1, 81-128.

Breiman, L. 2001 Random Forests. Machine Learning 45, 5-32.

Fonteneau, A., Pallarès, P., \& Pianet, R. 2000. A worldwide review of purse seine fisheries on FADs. In : Le Gall, J.Y. (ed.), Cayré, P. (ed.), Taquet, M. (ed.) Pêche thonière et dispositifs de concentration de poissons. Plouzané : IFREMER, (28), 15-35. (Actes de Colloques - IFREMER ; 28). Pêche Thonière et Dispositifs de Concentration de Poissons : Colloque Caraïbe-Martinique, Trois-llets (MTK), 1999/10/15-19. ISBN 284433-047-9. 
Guillotreau, P., Salladarré, F., Dewals, P., \& Dagorn, L. 2011. Fishing tuna around Fish Aggregating Devices (FADs) vs free swimming schools: Skipper decision and other determining factors.

Fisheries Research, 109(2-3), 234-242. https://doi.org/10.1016/j.fishres.2011.02.007

Harley, S.J., Davies, N., Hampton, J. and McKechnie, S. 2014. Stock assessment of bigeye tuna in the western and central Pacific Ocean. Western and Central Pacific Fisheries Commission, Scientific Committee, Tenth Regular Session, Majuro, Republic of the Marshall Islands. WCPFC-SC10-2014/SA-WP-01.

lanelli, J., Maunder, M. N., and Punt, A. E. 2012. Independent review of the 2011 WCPO bigeye tuna assessment. WCPFC-SC8-2012/SA-WP-01, Busan, Republic of Korea.

Kristensen, K., Nielsen, A., Berg, C.W., Skaug, H., and Bell, B.M. 2016. TMB: Automatic differentiation and Laplace approximation. Journal of Statistical Software, 70: 1-21.

Lopez, J., Moreno, G., Sancristobal, I., \& Murua, J. 2014. Evolution and current state of the technology of echo-sounder buoys used by Spanish tropical tuna purse seiners in the Atlantic, Indian and Pacific Oceans. Fisheries Research, 155, 127-137. https://doi.org/10.1016/j.fishres.2014.02.033

McKechnie, S., Hampton, J., Pilling, G.M. \& Davies, N. 2016. Stock assessment of skipjack tuna in the western and central Pacific Ocean. Western and Central Pacific Fisheries Commission, Scientific Committee, Twelfth Regular Session, Bali, Indonesia.

McKechnie, S., Pilling, G. \& Hampton, J. 2017. Stock assessment of bigeye tuna in the western and central Pacific Ocean. Western and Central Pacific Fisheries 
Commission, Scientific Committee, Thirteenth Regular Session, Rarotonga, Cook Islands.

Miyake, M. P., Guillotreau, P., Sun, C., \& Ishimura, G. 2010. Recent developments in the tuna industry—Stocks, fisheries, management, processing, trade and markets. (Technical Paper No. 543). Retrieved from Food and Agriculture Organization of the United Nations website: $\underline{\text { http://www.fao.org/3/a-i1705e.pdf }}$

NASA Goddard Space Flight Center, Ocean Biology Processing Group; 2014: MODIS-Terra 4 km2 Monthly Sea Surface Temperature Ocean Color Data, NASA OB.DAAC, Greenbelt, MD, USA. http://doi.org/10.5067/ORBVIEW-2/SEAWIFS_OC.2014.0. Accessed 2017/02/13. Maintained by NASA Ocean Biology Distributed Active Archive Center (OB.DAAC), Goddard Space Flight Center, Greenbelt MD

R Core Team 2019. R: A Language and Environment for Statistical Computing.

Suzuki, Z., Miyabe, N., Ogura, M., Shono, S., \& Uozumi, Y. 2003. Some important factors in controlling fishing capacity in tuna fisheries. In S. Pascoe \& D. Greboval (Eds.), Measuring Capacity in Fisheries (FAO Fisheries Technical Paper 445). Retrieved from http://agris.fao.org/agris-search/search.do?recor dID=XF2016019825

Wright, M.N. and Ziegler, A. 2017. Ranger: A Fast Implementation of Random Forests for High Dimensional Data in C++ and R. Journal of Statistical Software 77. 